\title{
Complutum
}

ISSN: 1131-6993

\section{Asentamientos polinucleares y resiliencia urbana entre el Bronce Final y la Edad del Hierro en el Sureste ibérico: nuevos datos a partir del Castellar de Librilla}

\author{
Benjamín Cutillas Victoria ${ }^{1}$; María Milagrosa Ros Sala ${ }^{2}$
}

Resumen. En el último período del Bronce Final se configuran en el Sureste ibérico una serie de asentamientos de gran entidad y dinamismo interno caracterizados por una ordenación inicial dispersa, materializada después en un urbanismo polinuclear y una destacada organización sociopolítica que pervive durante la Edad del Hierro. En este contexto, este artículo analiza el desarrollo de ese tipo de patrón de ocupación sobre diferentes complejos poblacionales establecidos a lo largo de la cuenca del Segura, profundizando especialmente en nuevos datos procedentes del Castellar de Librilla que arrojan luz sobre el desarrollo de su estructura espacial intraurbana. Las zonas de hábitat detectadas en las recientes intervenciones arqueológicas, algunas delimitadas por sistemas defensivos de envergadura, confirman las transformaciones que, desde el Bronce Final hasta el Ibérico Pleno, se producen en su configuración interna. Estos episodios de reestructuración y sinecismo urbanístico evidencian los procesos de adaptación que estos asentamientos polinucleares desarrollaron en el marco de las cambiantes dinámicas territoriales y culturales de la región durante el I milenio a.C.

Palabras clave: Bronce Final; Edad del Hierro; territorio; dinámicas de poblamiento; prospección intensiva; fortificaciones.

\section{[en] Polynuclear settlements and urban resilience between Late Bronze Age and Iron Age in the Iberian Southeast: new data from the site of Castellar de Librilla}

\begin{abstract}
In the last phase of the Late Bronze Age, a series of hilltop settlements, characterized by a first dispersed planning, were created in the Iberian Southeast. This planning turned into a polynuclear urbanism system and a significant socio-political organisation that continues during the Iron Age. In this article, we examine the development of this type of occupation pattern on different sites throughout the Segura basin and we present new data from the site of Castellar de Librilla to deepen in the development of its intra-urban spatial structure. The new habitat areas detected in recent archaeological surveys, some of them delimited by important defensive systems, allow us to observe the transformations in its internal configuration from the Late Bronze Age to Iberian Period. These episodes of urban restructuring show the adaptation processes that these polynuclear settlements developed within the framework of the changing territorial and cultural dynamics of the region during the 1st millennium BC.
\end{abstract}

Keywords: Late Bronze Age; Iron Age; settlement dynamics; archaeological survey; territory; fortifications.

Sumario. 1. Introducción. 2. La emergencia de los primeros oppida: una nueva forma de organización sociopolítica en el Sureste ibérico. 3. Un entorno en el que permanecer: dinámica territorial y estrategias económicas del Castellar de Librilla. 4. Los nuevos trabajos de prospección arqueológica sobre El Castellar de Librilla. 4.1. Planteamiento y metodología. 4.2. Resultados. 5. Reajuste poblacional y evolución intra-site: del Bronce Final reciente al período ibérico en el Castellar de Librilla. 6 Consideraciones finales. 7. Bibliografía.

Cómo citar: Cutillas Victoria, B.; Ros Sala, M. M. (2020). Asentamientos polinucleares y resiliencia urbana entre el Bronce Final y la Edad del Hierro en el Sureste ibérico: nuevos datos a partir del Castellar de Librilla. Complutum, 31 (1): 71-96.

\footnotetext{
1 Investigador Predoctoral FPU - Universidad de Murcia

Departamento de Prehistoria, Arqueología, Hist. Antigua, Hist. Medieval y CCTT. Historiográficas. Facultad de Letras. Universidad de Murcia.

E-mail: benjamin.cutillas@um.es ORCID: https://orcid.org/0000-0002-6358-4176

2 Profesora Titular del Área de Prehistoria

Departamento de Prehistoria, Arqueología, Hist. Antigua, Hist. Medieval y CCTT. Historiográficas. Facultad de Letras. Universidad de Murcia.

E-mail: milaros@um.es ORCID: https://orcid.org/0000-0002-3597-0870
} 


\section{Introducción}

La evolución de las comunidades locales del I milenio a.C. del Sureste ibérico se ha analizado, con demasiada frecuencia, bajo el prisma de las dinámicas externas e influencias foráneas. A partir de las consecuencias de procesos de especial entidad como la colonización fenicia, la frecuentación púnica o la presencia de comerciantes griegos, se ha construido una historia sobre los grupos culturales locales parcelada por estos fenómenos de origen foráneo. No hay duda alguna en valorar el peso de la presencia de estos actores en la configuración de la idiosincrasia de los territorios y los pueblos que habitaron esta región; precisamente estas sociedades locales son el claro ejemplo de los efectos que provocan las dinámicas del encuentro y lo que suponen en términos de interacción e hibridación cultural (Van Dommelen 1998; Vives-Ferrándiz 2005; Dietler 2009). Sin embargo, no es menos cierto que la perspectiva desde la alteridad emprendida tradicionalmente ha dificultado un análisis transversal sobre la evolución progresiva que experimentan las últimas sociedades fijadas a los territorios de este sector de la Iberia mediterránea durante el último período del Bronce Final hasta los siglos IV-III a.C.

La falta de estudios de alcance prolongado focalizados en las sociedades locales afecta especialmente a las coyunturas de transición, como la que tiene lugar entre finales del siglo VI y el V a.C. al sucederse un cambio de los modelos sociopolíticos desarrollados durante el final del Bronce Final y el Hierro Antiguo, y los comienzos del mundo ibérico. Es cierto que la compartimentación de estos períodos se apoya en transformaciones profundas a nivel territorial, económico o material, con modificaciones importantes de los sistemas en los que desaparecen unos escenarios y surgen otros nuevos. No obstante, existen una serie de asentamientos de gran arraigo, al menos desde el siglo IX a.C., cuyas comunidades se sobreponen a esos procesos de reestructuración y variabilidad de las condiciones socioeconómicas del sistema, siendo capaces de ejercer una elevada resiliencia al adaptarse a la nueva coyuntura en sus diferentes esferas socioculturales. Incluso cuando su propio desarrollo se ve empujado a una serie de desplazamientos y traslados de los sectores urbanos dentro del mismo complejo habitacional, lo que obliga a la reestructuración de áreas residenciales, zonas productivas y construcción de nuevos sistemas defensivos. Este dinamismo es el que les permite perdurar en el tiempo, cobrando especial relevancia cuando se trata de núcleos de primer orden cuya posición permite reconocer su papel destacado, en algunos casos con perduración excepcional, en los entramados sociopolíticos del sector en estudio.

La contribución aquí presentada aporta nuevos datos en torno a esta cuestión procedentes de varios asentamientos de entidad similar que marcaron el devenir político, económico y territorial del eje prelitoral que se dibuja entre la depresión de Vera y la desembocadura del Segura. Tras el análisis global sobre los núcleos más significativos a partir de los datos publicados, se realiza una aproximación particular a uno de los principales entornos urbanos de la zona mediante los últimos resultados de los trabajos de campo realizados en El Castellar de Librilla (Librilla, R. Murcia). Bien conocido gracias a las excavaciones desarrolladas en el sitio durante el primer lustro de la década de los años ochenta del siglo pasado (Ros 1989), los resultados de una reciente prospección arqueológica amplían y precisan el conocimiento que se tenía de la planificación y evolución urbanística de este núcleo, aportando nuevos anclajes a futuras investigaciones en los restantes asentamientos analizados. Los resultados de estas últimas intervenciones justifican una lectura renovada de las dinámicas intra-site que se dan en este complejo que no solo se constriñe al yacimiento citado, sino que incluye bajo su órbita al cercano Cabezo de la Fuente del Murtal, en la margen derecha de la Rambla de Algeciras. En este contexto de desarrollo, el interés de este enclave en la discusión actual del Sureste ibérico (Fig. 1) reside en su papel como asentamiento principal, con datos contrastados de su evolución en períodos de amplio dinamismo económico en contraste con otros de cambios en dicho espectro (Ros 1989), y que tienen cabida dentro de un esquema urbanístico que sigue una trama no concentrada o dispersa, pero que se encuentra completamente articulada. Este tipo de patrón de ocupación se define como polinuclear en tanto supone el desarrollo de un determinado conjunto poblacional en núcleos cercanos y que comparten un espacio común y una unidad sociopolítica propia. Así, en base a las cuestiones presentadas y que serán abordadas a lo largo de este trabajo, es factible profundizar en el conocimiento de las diferentes y tan problemáticas etapas de transición que se detectan en el I milenio a.C. Unas transformaciones que alcanzan no solo el contexto que se da entre el Bronce Final reciente y el Hierro Antiguo, sino también entre esta última fase y aquella en la que tiene lugar la emergencia de la cultura ibérica. 


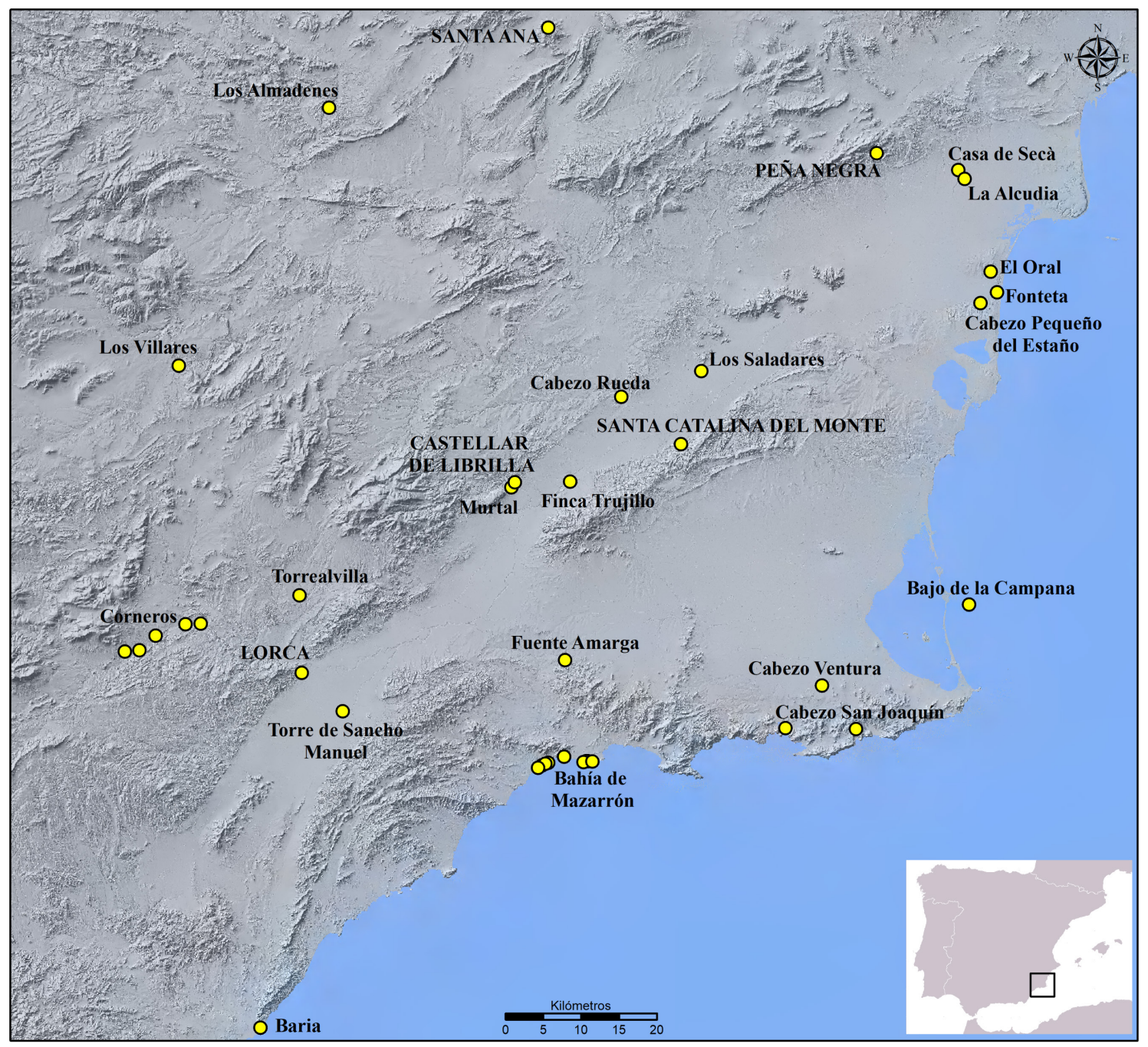

Fig. 1. Mapa del sector central del Sureste ibérico con indicación de los enclaves principales citados en el texto. (Fuente: Elaboración propia - MDT IGN).

2. La emergencia de los primeros oppida: una nueva forma de organización sociopolítica en el Sureste ibérico

La colonización fenicia del litoral del Sureste ibérico se ha planteado como uno de los factores más determinantes en el desarrollo político y territorial de la región a partir del siglo VIII a.C. La interacción entre las comunidades autóctonas y los entornos coloniales generó una época de crecimiento y aumento demográfico que repercutió en los paisajes habitados con la creación de nuevos asentamientos y puntos de frecuentación colonial. Sin embargo, estas dinámicas se apoyan en una tendencia iniciada al menos una centuria antes, durante el Bronce Final. En el siglo IX a.C. se produce una intensa reordenación poblacional motivada por estímulos generados a partir de los contactos con los círculos comerciales atlántico y centromediterráneo, configurando una serie de nuevos territorios y organizando sus actividades productivas en torno a un sistema económico favorable que explica el interés de los fenicios por los recursos y los mercados de la región. No obstante, estos cambios de ciclo no solo son visibles a nivel macroespacial, sino que también tienen una incidencia notable en los procesos intra-site de los asentamientos. La voluntad por adaptarse a las nuevas coyunturas lleva consigo la reorganización de los espacios urbanos en los asentamientos coetáneos, incluyéndose en estos procesos la construcción de nuevos tramos defensivos, lo que implica una significativa micromovilidad dentro de lo que fue un mismo asentamiento que perdura pese a esta reorganización de las zonas habitadas. 
Este nuevo escenario se encuentra bien determinado en el espacio que se abre entre la zona de paleodesembocadura de los ríos Segura y Vinalopó y la sierra de Crevillente, donde aproximadamente tras la desaparición del asentamiento fortificado de Caramoro II (García Borja et al. 2010; Jover et al. 2016) se produce la fundación en la segunda mitad del siglo IX a.C. del centro de primer orden de Peña Negra (González Prats 1990: 105). La localización de este último en un enclave privilegiado, bien situado respecto a las vías de comunicación y con una actividad productiva diversificada (Lorrio et al. 2017: 86-89), le permitió desarrollar una entidad urbana con modelos arquitectónicos que, en su fase inicial PN I-, siguen la tradición constructiva basada en estructuras de tipo circular y oval con alzados de materiales ligeros y perecederos (González Prats 1990: 36-39); un modelo que también se ha documentado en el mismo horizonte cronológico en La Serrecica de Totana (Lomba 1995), Los Cabezuelos de Jaén (Contreras 1982; Dorado et al. 2015) o en el Peñón de la Reina en Alboloduy (Martínez y Botella 1980). El desarrollo del asentamiento se asocia en esta fase a una importante actividad metalúrgica y alfarera (González Prats y Lorrio, inédito) que no solo se focalizó en este punto de la sierra de Crevillente, sino que también debe ponerse en relación con la rearticulación de una red importante de asentamientos rurales concentrados en la llanura aluvial de Crevillente relacionados con actividades de explotación primaria y trabajos metalúrgicos (Trelis et al. 2004; García Borja et al. 2007; García Borja y Pérez Jordà 2012; Soriano et al. 2012)

Sobre este tejido territorial y los modos de organización interna propios que se desarrollan en este último período del Bronce Final, el núcleo de Peña Negra enfrentó la instalación definitiva de los fenicios en la desembocadura del Segura en la primera mitad del siglo VIII a.C., primero con la creación del establecimiento fortificado del Cabezo Pequeño del Estaño y, posteriormente, la fundación de Fonteta (Rouillard et al. 2007; González Prats (ed.) 2011; Renzi 2013; Menárguez y Prados 2014; Prados et al. 2018). El inicio de esta nueva etapa en la que se produce una intensificación progresiva de las actividades productivas y comerciales, se tradujo en el asentamiento local en una nueva fase de remodelación urbana identificada como PN II. Desde la segunda mitad del siglo VIII a.C. y hasta el abandono del yacimiento en una fecha próxima al 550 a.C., se produce un desarrollo de los equipamientos urbanísticos con la construcción de estructuras públicas defensivas y aterrazamientos, junto a viviendas que ampliaban su tamaño y complejidad (González Prats 1990: 96; Lorrio et al. 2016); una realidad que también se deja notar en la esfera funeraria con la fase de transición que acaba en Moreres II con la generalización del uso de urnas a torno como contenedores cinerarios (González Prats 2002: 381-383). Esta expansión del asentamiento en sus diversos sectores (Fig. 2A) debió proporcionar a Peña Negra un aspecto de núcleo urbano de gran envergadura en el que, además de contar con una muralla perimetral, las últimas investigaciones apuntan a la construcción de un segundo recinto amurallado en una posición elevada al interior del asentamiento a modo de acrópolis (Lorrio et al. 2016: 39). Este sector reservado al establecimiento de las jefaturas acabaría por terminar de configurar un espacio urbano, jerarquizado y ordenado, capaz de transmitir la imagen del poder de esta comunidad no solo sobre su asentamiento, sino sobre su territorio inmediato como demuestra la construcción de diversos fortines a lo largo del siglo VII a.C., como Les Barricaes y El Cantal de la Campana, con el principal objetivo de controlar los accesos al asentamiento desde el valle de Aspe y el corredor del Vinalopó (Trelis y Molina 2017: 173).

La imagen de Peña Negra II refleja algunas de las características clave que estos centros principales del Sureste ibérico desarrollan a nivel político y territorial desde estructuras que arrancan en la fase anterior. Esta continuidad sobre la que se asienta el importante desarrollo a partir del siglo VIII a.C. es la que se encuentra en otros núcleos de la región, aunque contemos con un conocimiento menor sobre sus dinámicas evolutivas. Un caso particular dentro de este mismo proceso se encuentra en uno de los corredores principales que une el tramo medio del Segura con la cuenca alta y media del Vinalopó: el complejo habitacional de la sierra de Santa Ana (Jumilla, Murcia). Los hallazgos de una serie de materiales asociados a los siglos $\mathrm{X}$ y IX a.C. hallados en Coimbra del Barranco Ancho (Ros 1990) marcan el inicio de una ocupación polinuclear cuya disposición se dispersaba por distintos sectores del relieve (Fig. 2B). En este sentido, destaca la aparición de un hacha de cubo de tipo tautón y dos anillas de tipología atlántica localizadas en el Pico del Maestre (Molina y Molina 1991; Simón et al. 1999), o las tumbas más antiguas de la necrópolis tumular del Collado y Pinar de Santa Ana (Hernández y Gil 2001-2002) cuyos contenedores cinerarios 
guardan estrechos paralelos con Peña Negra y Les Moreres I (González Prats 1983; González Prats 2002; Lorrio 2008: 233-234). La transición de Santa Ana hacia la fase siguiente se refleja en la continuidad de parte de las sepulturas de la necrópolis del Collado y Pinar, donde se percibe una rápida introducción de producciones torneadas y bienes de prestigio foráneos, como cuchillos de hierro o vasos de alabastro (Hernández y Gil 2001-2002). Esta fase de intensificación de los contactos con los entornos coloniales también se percibe en Coimbra del Barranco Ancho, como demuestra el hallazgo de un borde de pithoi a torno de asas geminadas que define un horizonte anterior al desarrollo posterior del hábitat ibérico (García Cano 1997) y evidencia la continuidad del enclave a lo largo de toda la Edad del Hierro.

Retomando el eje prelitoral que forman las cuencas de los ríos Guadalentín y Segura, próximo a la confluencia entre ambas arterias fluviales, se sitúa el yacimiento de Santa Catalina del Monte. A pesar de su extensa secuencia cronoestratigráfica, la investigación sobre este asentamiento está marcada por las limitaciones que impone la conversión de su superficie en área urbanizable. Con todo, y pese a lo escaso de su superficie excavada, los datos con los que actualmente contamos revelan una ocupación del asentamiento en el último período del Bronce Final reciente (Ros 1986-1987: 87) y una expansión del espacio habitado en el período inmediatamente posterior (Fig. 2C). Durante el siglo VII a.C. se produce una fase de desarrollo en la que, a tenor de lo que ocurre en el resto de la región, el espacio habitado de Santa Catalina se ve inmerso en una importante remodelación urbana en la que las casas del asentamiento se modifican y se detecta una mayor vinculación con las actividades transformativas del metal (Ros 1986-1987). Además, las zonas residenciales se amplían (Poyato 1976-1978; Ros Sala 1986-1987; Bellón y Martínez 2011) y se lleva a cabo una intensa labor de adecuación del terreno con la creación de muros terrazas para intentar ganar superficie a la acusada ladera sobre la que se levantó el asentamiento (Ros 1986-1987: 85). La importancia de este enclave respecto a su territorio inmediato se demuestra al no sufrir ningún tipo de abandono o ruptura poblacional entre el Hierro Antiguo y el período ibérico, sino que precisamente en la transición que se produce durante el siglo V a.C. se sientan las bases sobre las que se desarrollará uno de los centros ibéricos principales del Sureste, con la expansión del espacio ocupado desde el castillo de La Luz (Comino 2016: 54) hasta, al menos, el convento monacal de Santa Catalina (Ros 1986-1987; Ruiz 1998; Bellón y Martínez 2011), la formación de una extensa necrópolis en la que se han documentado más de 600 tumbas (Nieto 1947; García Cano 1998) y la construcción del importante santuario de La Luz (Lillo 1999; Comino y Tortosa 2017).

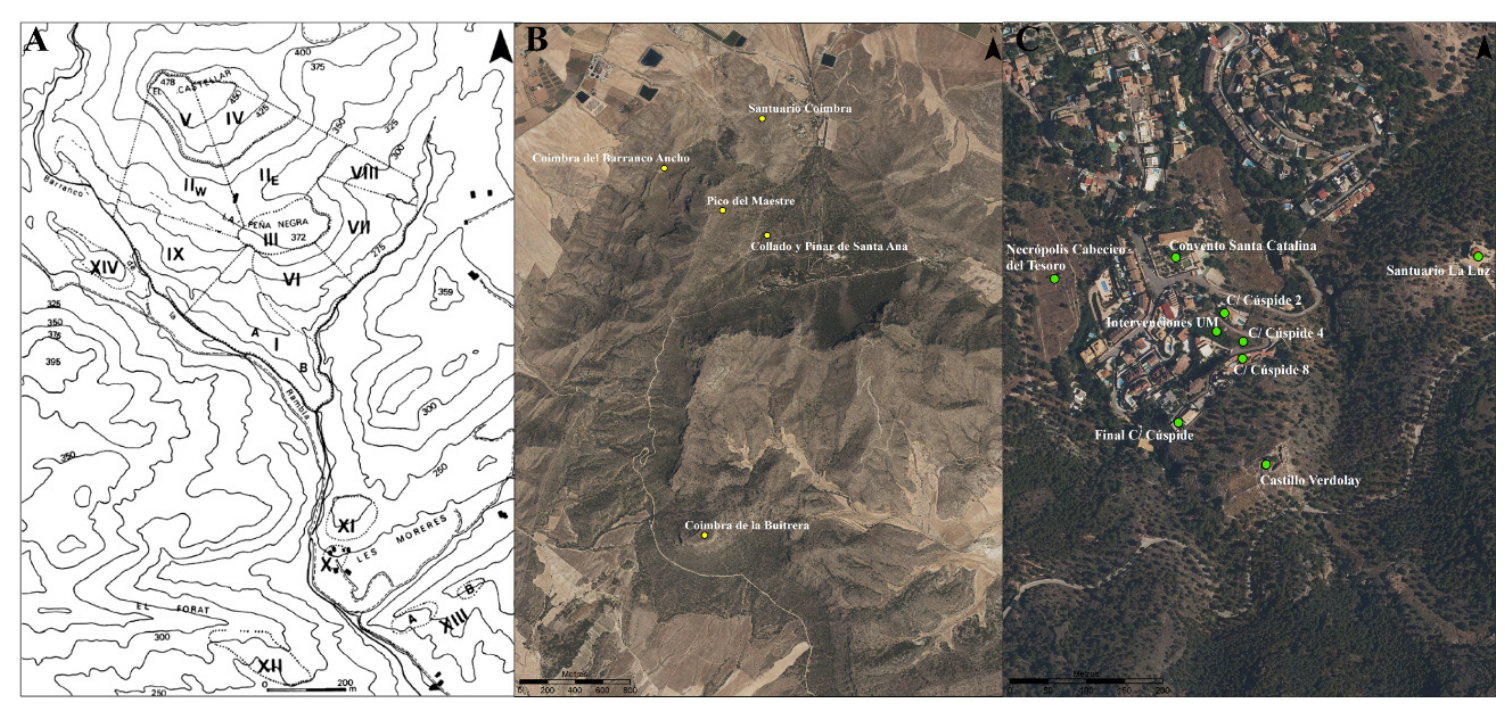

Fig. 2. A. Asentamiento polinuclear de Peña Negra según González Prats (1983); B. Yacimientos arqueológicos del Bronce Final y Hierro Antiguo en el complejo poblacional de la sierra de Santa Ana (Elaboración propia. PNOA - IGN); C. Intervenciones arqueológicas en el complejo polinuclear de Santa Catalina del Monte (Elaboración propia. PNOA - IGN). 
El núcleo que guarda más en común con Peña Negra es el Castellar de Librilla. Ambos juegan un papel muy similar en el contexto de la primera mitad del I milenio a.C., con unas dinámicas urbanísticas, productivas y socioculturales que son casi paralelas y que tienen más cosas en común que diferencias, construyendo los prototipos del centro urbano de poder para estos territorios y esta cronología. Además, en los últimos trabajos de prospección que se tratarán a continuación, se han hallado una serie de materiales que permiten retrasar la fundación del asentamiento al siglo IX a. C. Se trata concretamente de varias fuentes carenadas de las mismas características que las halladas en Coimbra del Barranco Ancho (Ros 1990) y Caramoro II (García Borja et al. 2010: 47), pero con paralelos evidentes en las fases iniciales de Los Saladares (Arteaga y Serna 1975: 92, Lám. II), Peña Negra I (González Prats 1979: 104-105) o el Barranc del Botx (García Borja et al. 2007: 100). Por tanto, esta primera ocupación del Bronce Final reciente se encuadra dentro de las dinámicas de reajuste territorial propias del período, lo que pone en evidencia la complejidad y la consolidación de las estructuras políticas y sociales de estas comunidades con anterioridad a la instalación de las colonias fenicias en el Sureste, así como su posterior perduración en el tiempo.

A partir de la segunda mitad del siglo VIII a.C. el Castellar de Librilla comienza una una fase importante de desarrollo y expansión urbanística que afecta tanto a los sectores localizados en el piedemonte durante las intervenciones de los años 80 (Ros 1989), como en las zonas de cima del sistema que se han identificado durante las prospecciones arqueológicas que aquí se analizan. Un desarrollo sincrónico al de Peña Negra que coincide, además de con la llegada de las influencias coloniales del Bajo Segura, con el incipiente entorno colonial que se asienta sobre la Bahía de Mazarrón (Ros 2017). En esta nueva coyuntura el asentamiento amplía su espacio urbano y arquitectónico con viviendas de planta compleja, el desarrollo de sistemas productivos que ganan protagonismo en un área artesanal localizada junto a la rambla que cuenta con estructuras de tratamiento del hierro y alfareras (Ros 1989), y la construcción de distintos sectores amurallados tanto en el propio Castellar como en el cercano Cabezo de la Fuente del Murtal. No obstante, al igual que sucede en Santa Catalina, la diferencia que los asentamientos del Bajo Segura-
Guadalentín guardan respecto a Peña Negra es la entidad que desarrollaron hasta época ibérica, manteniendo su posición territorial y actividades productivas, aunque para ello tuvieron que realizar profundas transformaciones en sus propios asentamientos.

Se pone de esta manera en valor un nuevo tipo de asentamiento unitario y fortificado, de distribución espacial dispersa y que no puede comprenderse de manera desligada. La consolidación de estos centros cristaliza en un modelo de ocupación que caracteriza los núcleos de primer orden del horizonte autóctono del Sureste y cuya urbanística por sectores les permitió construir un esquema urbano capaz de acceder tanto a los recursos agropecuarios como a las posiciones de control visual en altura. Estas son las características urbanísticas que permiten entrever en ellos los primeros oppida de la región sobre cuya evolución se terminarán de desarrollar en la Segunda Edad del Hierro los centros de poder que regirán los grupos culturales ibéricos.

\section{Un entorno en el que permanecer: dinámica territorial y estrategias económicas del Castellar de Librilla}

Las intervenciones arqueológicas realizadas sobre la sierra de El Castellar y el tramo medio de la Rambla de Algeciras (Ros 1989; García Blánquez 1996; Lomba y Cano 2002) pusieron de manifiesto la existencia de un denso poblamiento articulado desde, al menos, el Bronce Final reciente que se prolonga hasta el siglo IV a.C. (Ros 1989). Las estructuras de hábitat y producción identificadas en diferentes áreas del Cabezo de la Fuente del Murtal y del Castellar, a ambas vertientes de este cauce que conecta el valle del Guadalentín con la cuenca interior de los ríos Pliego y Mula, generó un paisaje urbano disperso que no puede entenderse de forma desconectada, sino bajo una única entidad poblacional cuyas respuestas, problemáticas y transformaciones deben interpretarse de manera coral. Un modelo de organización y desarrollo urbanístico que, como ya se ha visto, no es exclusivo de este yacimiento, sino que se repite en otros núcleos del Sureste entre los que destaca por su similar posición sociopolítica el núcleo urbano de Peña Negra (González Prats 1983; Lorrio et al. 2016). A partir de una primera ocupación del Castellar en el marco de las dinámicas de expansión 
territorial del último horizonte del Bronce Final, marcadas por la creciente relación con el mediodía peninsular y la Alta Andalucía (Molina 1978: 218-219; Ros 1989: 324; Jover et al. 2016: 95), y la presencia consolidada de las influencias del círculo atlántico en el Sureste (González Prats 1990; Trelis et al. 1996; Simón et al. 1999), se desarrollan seis fases de ocupación posteriores que demuestran la fijación, el arraigo y el desarrollo de la comunidad allí establecida.

Esta continuidad se asienta sobre la estrecha relación con las posibilidades del medio natural que le rodeaba (Fig. 3). A pesar de tratarse de un paisaje muy afectado por la creciente aridez y los procesos erosivos que se inician en el Sureste ibérico desde el III milenio a.C. (Calmel-Ávila 2000; Ros et al. 2014; Carrión et al. 2018), la disponibilidad de recursos hídricos no fue un problema para este enclave. La localización inmediata de dos fuentes naturales - una en el propio Castellar y otra a los pies del Cabezo de la Fuente del Murtal- completaba el caudal de la rambla de Algeciras que, a su vez, regaba las vertientes inmediatas con los aportes erosionados de otros sistemas situados rambla arriba (Calmel-Ávila 2002: 105-106).
Este paisaje acabaría configurando un pequeño entorno marcado por la elevada potencialidad agrícola de sus tierras, lo que destacaba en una región caracterizada por los paisajes semiáridos y explica que el nombre de Algeciras, con el que se denomina a esta rambla subsidiaria del río Guadalentín, proceda del topónimo árabe de al-Ğazīra al-Hadrā o isla verde. Además de los recursos citados, a los que se podría sumar la explotación de arcillas de la rambla destinadas a las alfarerías locales, esta zona destaca por contar en sus cercanías con afloramientos de hierro, cobre, galena y metales nobles localizados en las cercanas sierras de Espuña, Carrascoy, La Tercia y Cabezo Gordo (Ros 1993: 73; Arana y Pérez 1993: 127; Puente 2015), sentando las bases del trabajo metalúrgico del hierro que se realizó en el poblado desde la segunda mitad del siglo VIII a.C. (Ros 1989: 166). La obtención de recursos forestales como combustible para las estructuras metalúrgicas $\mathrm{N}$ y $\mathrm{E}$, así como para el horno alfarero $\mathrm{M}$ y las propias actividades cotidianas de la comunidad, no suponía tampoco un problema al encontrarse de manera abundante en la propia sierra del Castellar y la cercana sierra de la Muela (Grau Almero, inédito).

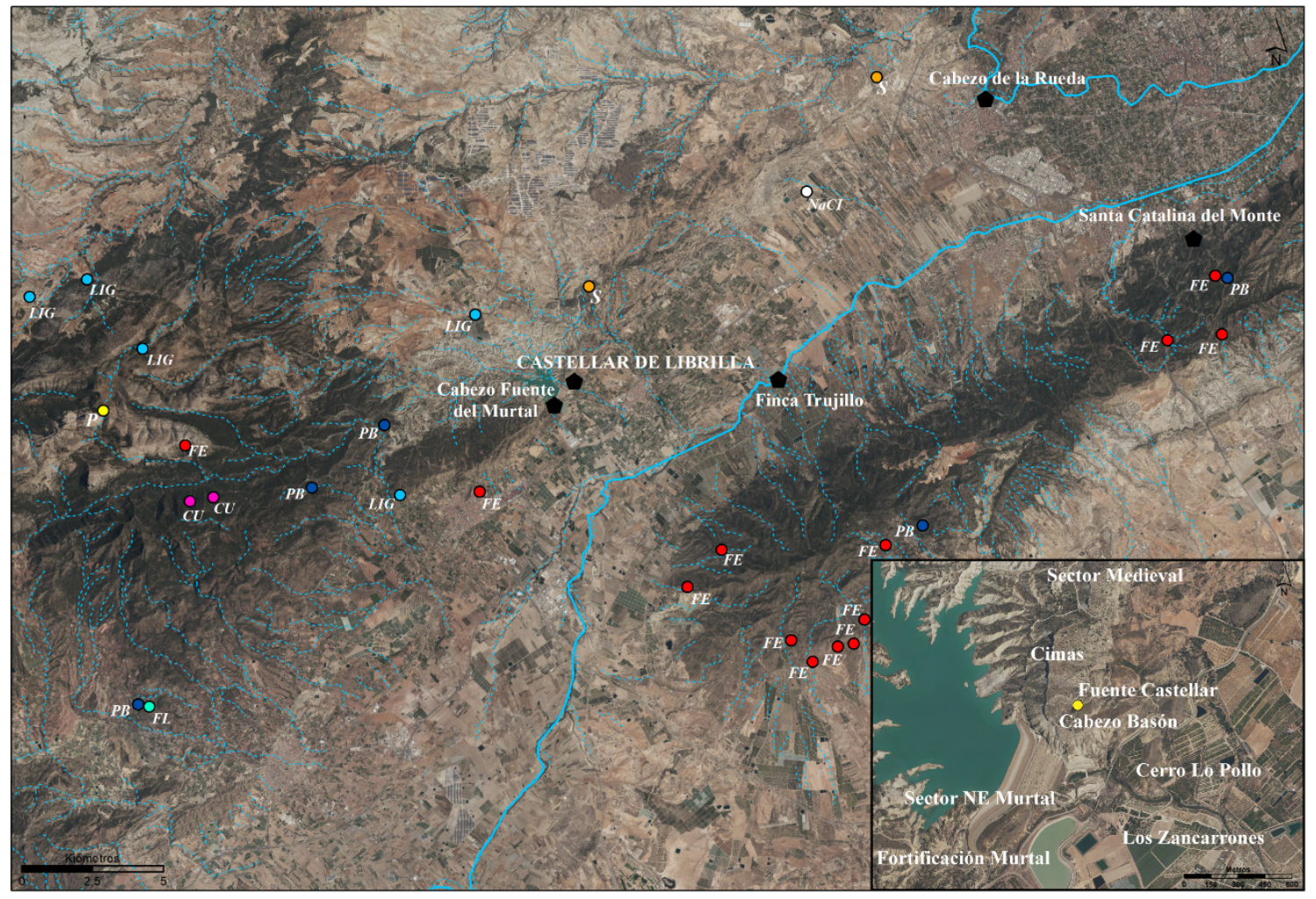

Fig. 3. Cartografía mesoespacial del Castellar de Librilla en relación a la red hídrica de su entorno inmediato y a los recursos metalogenéticos disponibles. En detalle, diversos sectores del complejo poblacional (Fuente. Elaboración Propia - PNOA IGN - Metalogenia IGME) 
La centralización de las actividades transformativas en el asentamiento compartió espacio con barrios habitacionales, lienzos amurallados y espacios funerarios, lo que dotaba a este núcleo urbano de una apariencia compleja y reforzada por su posición en altura respecto a su entorno inmediato. El emplazamiento del Castellar primero, y en combinación con el Cabezo de la Fuente del Murtal después, responden a posiciones geoestratégicas bien defendidas tanto por sus características naturales, como por los sistemas fortificados que se construyen para incrementar sus estrategias defensivas y proyectar una imagen simbólica del poder de esta comunidad latente en la potencia de las estructuras acometidas. Precisamente estas obras estaban destinadas a ejercer un control privilegiado de la cuenca del Guadalentín, la de Mula y, un factor de especial importancia, de la conexión de la primera con la entrada a la rambla de las Moreras que conecta directamente con la Bahía de Mazarrón. Como el prelitoral, este territorio litoral se encontraba culturalmente formado desde épocas anteriores del Bronce, en período argárico, Tardío y Final (Ros 2017; Ros y Cutillas e.p.). Sin embargo, vive una época de intenso desarrollo a partir del siglo VIII a.C. ligada a la instalación de establecimientos fenicios y púnicos que persiguen explotar los abundantes recursos mineros de la zona y la entrada en contacto con los mercados y núcleos locales del prelitoral (Ros 2017). No obstante, este eje de comunicación no se detiene en la cuenca del Guadalentín, sino que aprovechando pasos naturales como el de la rambla de Algeciras se proyecta en sentido sur-norte hacia territorios del interior como el Noroeste murciano o el tramo medio-alto del Segura. La posición del Castellar respecto a esta coyuntura es sumamente ventajosa, aprovechando no solo los tránsitos en sentido este-oeste que le conectan con las desembocaduras de los ríos Segura y Almanzora, sino que se beneficia de las redes ya establecidas con el litoral durante el Bronce Final (Ros 1989) para mantener su desarrollo al amparo de las nuevas dinámicas económicas y comerciales establecidas con los asentamientos coloniales.

La ubicación de este asentamiento responde a la existencia de una economía diversificada y claramente planificada en la que la dinámica de intercambio intraterritorial de recursos entre los circuitos locales se amplió con el comercio de origen foráneo de filiación fenicia y púnica.
Desde mediados del siglo VIII a.C., El Castellar se encuentra plenamente integrado en los circuitos comerciales que se inician con la colonización fenicia del Sureste (Rouillard et al. 2007; González Prats (ed.) 2011; García Menárguez y Prados 2014) como demuestra una primera fase de desarrollo urbanístico y la incorporación de la cerámica a torno que alcanza en esta segunda mitad de la centuria el 46,35\% del total del registro vascular (Ros 1989: 301). A finales del siglo y durante todo el VII a.C., el poblado vive una fase de amplia expansión económica y demográfica -Librilla III- sustentada en la intensificación comercial de las relaciones iniciadas en la fase anterior y la construcción de una estructura metalúrgica para el trabajo del hierro en el mismo asentamiento. Todo ello provoca una nueva remodelación en la que se traza un urbanismo ordenado, con calles y viviendas más amplias que ahora presentan equipamientos internos complejos y enlucidos rojos y amarillos con motivos decorativos. Esta serie de remodelaciones en profundidad reflejan el nivel socioeconómico que el poblado alcanza en este período, convertido en un centro productor y redistribuidor de bienes y productos cuya tendencia se incrementa en la primera mitad del siglo VI a.C. (Ros 1988).

En este momento se produce con seguridad la ampliación del hábitat al otro lado de la rambla de Algeciras con la construcción de la fortificación del Cabezo de la Fuente del Murtal (Fig. 4) y los espacios productivos del Castellar ganan protagonismo como sucede en el área productiva junto a la rambla, donde se construye, al menos, una segunda estructura metalúrgica para el trabajo del hierro (Ros 1989: 142-143) y un horno alfarero complejo del que se conserva parte de la cámara de cocción y la de combustión (Ros 1989: 139). Este barrio artesanal va a ser fundamental para la comprensión de la etapa siguiente, ya que pese a que en la segunda mitad del siglo VI a.C. e inicios del siglo $\mathrm{V}$ a.C. se desdibuja el modelo colonial fenicio en el Sureste en favor de una creciente presencia tardoarcaica, como sucede en Baria/Villaricos (López Castro et al. 2011), Punta de los Gavilanes (Ros y Cutillas e.p.) o El Oral (Abad y Sala 2001), estas estructuras siguen funcionando en un entorno de barrio artesanal que deja inhabilitadas para su fin algunas de las viviendas cercanas que incluso son invadidas por las escombreras de los hornos inmediatos (Ros 1989: 150, 183). Durante el siglo V a.C. y su transición hacia 
el Ibérico Pleno se produce una última contracción urbana del asentamiento, en la que El Murtal se abandona y se levanta una muralla perimetral que cierra el núcleo por el cerro de
Lo Pollo (Fig. 4), delimitando además en su exterior una nueva área de necrópolis correspondiente a este último período cronológico de la ocupación del Castellar de Librilla.

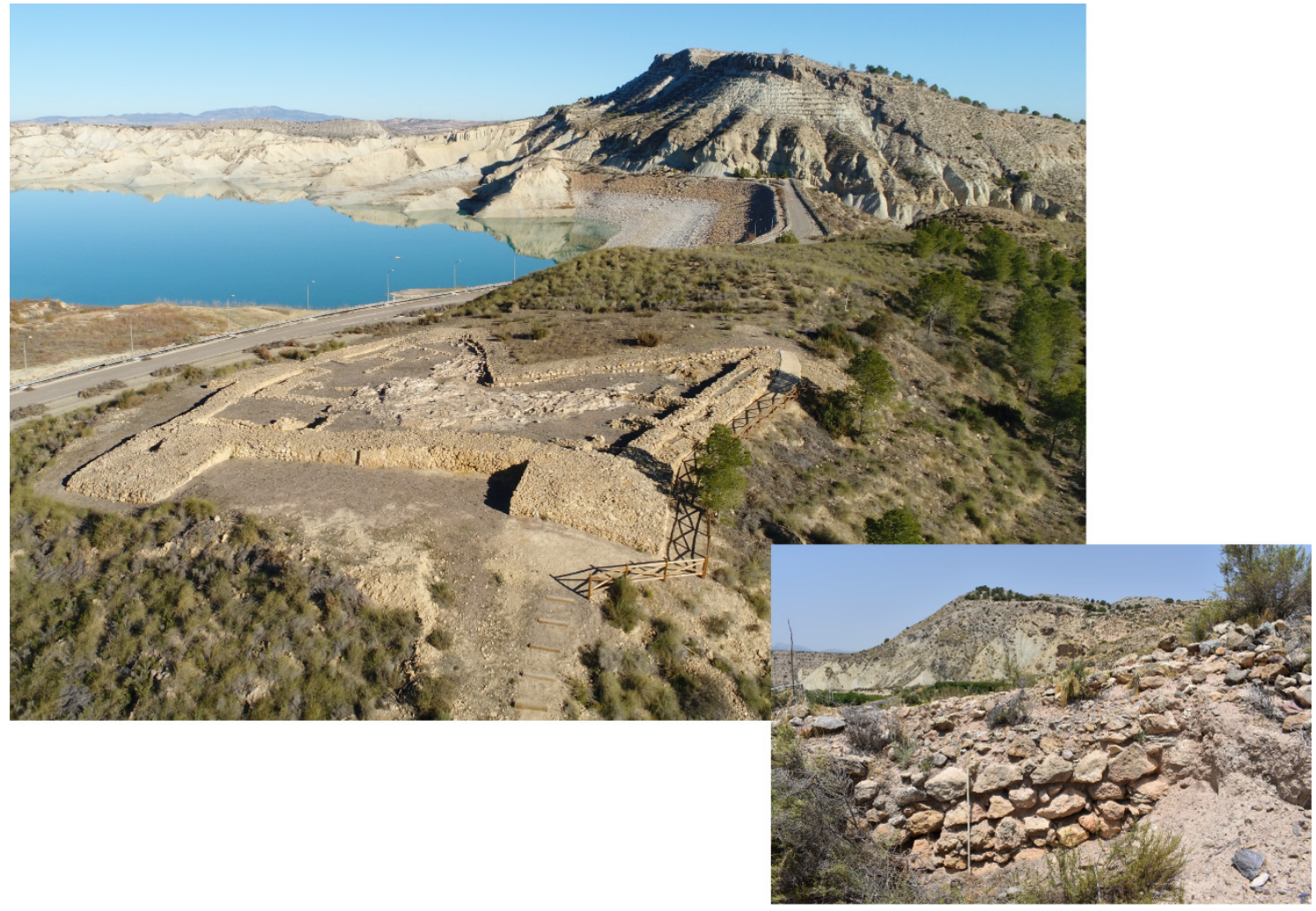

Fig. 4. Imagen aérea de la fortificación del Cabezo de la Fuente del Murtal y, al fondo, las cumbres del Castellar de Librilla (Fuente: Proyecto Murtal). En detalle, imagen del lienzo ibérico excavado en 1984 en el Cerro de Lo Pollo (Imagen de los autores).

\section{Los nuevos trabajos de prospección ar- queológica sobre el Castellar de Librilla ${ }^{3}$}

\subsection{Planteamiento y metodología}

La necesidad de llevar a cabo una nueva intervención sobre El Castellar de Librilla surge a raíz de la aparición en los últimos años de una serie de estructuras debido a la incidencia de los procesos erosivos en su cima y laderas superiores. Las vertientes la sierra de El Castellar fueron objeto de las intensas actividades

\footnotetext{
En este punto queremos destacar la colaboración y el buen hacer de Óscar González Vergara, Ana María García Sánchez, Alberto López López, María Navarro Fernández y Gonzalo Castillo Alcántara, arqueólogos colaboradores en las tareas de prospección durante la campaña de 2019 autorizada por la Dirección General de Bienes Culturales de la Comunidad Autónoma de la Región de Murcia con fecha 5 de marzo de 2019 (Ref: CTC/DGBC/SPH; Exp: 41/2019).
}

de reforestación que, a partir de $1970^{4}$, se realizan en los relieves que jalonan la cuenca del río Guadalentín. Esta técnica consistía en crear aterrazamientos artificiales por medios mecánicos y repoblar las superficies creadas con plantaciones masivas de pinos que permitieran fijar los suelos y detener la erosión ${ }^{5}$, ocasionando un importante impacto medioambiental al seccio-

\footnotetext{
Estas actividades de reforestación ya se venían realizando en las cuencas del Segura y el Guadalentín desde finales del siglo XIX, si bien es cierto que a partir de esta fecha es cuando tienen mayor impacto, en parte gracias al desarrollo de los medios mecánicos con los que aterrazar las laderas de los montes.

El aspecto del paisaje de los relieves de la zona cambió drásticamente al modificar las pendientes de estas elevaciones con la sucesión de terrazas que perdura hasta la actualidad. Sin embargo, esta técnica se ha acabado revelando como perjudicial en tanto que, en medios geográficos muy frágiles como los semiáridos, incrementa precisamente los procesos erosivos que se querían mitigar (Romero y Belmonte 2008: 102).
} 
nar con maquinaria pesada las pendientes de los montes, destruyendo los suelos originales, la vegetación existente $\mathrm{y}$, como ha sucedido en este caso, el propio registro arqueológico. Sin embargo, el ataque en la última década de la especie "tomicus destruens" ha provocado que un alto porcentaje de esta población vegetal se haya secado y haya sido talada en diferentes actuaciones por parte de la administración, provocando la aceleración de la pérdida progresiva de los suelos y paredes margosas que conforman la sierra de El Castellar ante la falta de sujeción natural, un efecto acrecentado por las precipitaciones estacionales comunes en la zona.

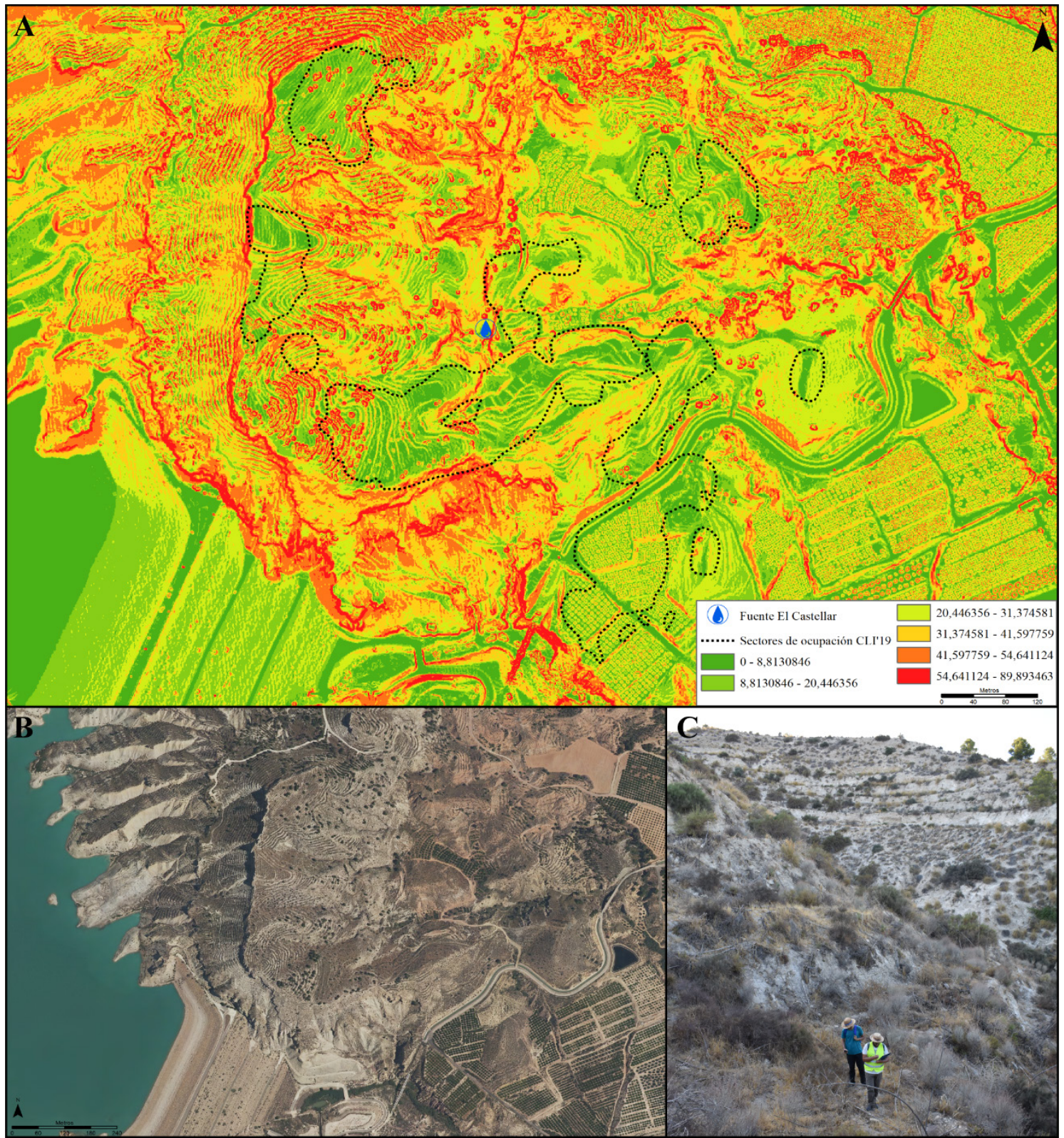

Fig. 5. A. Mapa de pendientes del complejo poblacional del Castellar de Librilla con áreas de mayor concentración de evidencias materiales destacadas (Elaboración propia. MDT - IGN). B. Imagen actual del Castellar de Librilla en el que se aprecian los efectos de los diversos aterrazamientos artificiales que han modificado su superficie (Elaboración propia. PNOA - IGN). C. Tareas de prospección arqueológica en la que se aprecian con claridad las terrazas actuales (Archivo de los autores).

Como consecuencia de este fenómeno, en los últimos años se estaban comenzando a detectar gran cantidad de materiales arqueo- lógicos y construcciones correspondientes al período de ocupación del asentamiento en zonas inéditas hasta el momento. Además, la 
persistencia de esa erosión pluvial y eólica está afectando especialmente a las estructuras protohistóricas, lo que fundamentaba una primera intervención como la que aquí se presenta para examinar su disposición y estado de conservación. Así, la prospección arqueológica planteada se encontraba destinada a documentar de manera intensiva la dispersión espacial de estas evidencias arqueológicas con el objetivo de definir nuevas áreas de ocupación hasta hoy desconocidas, pero que fueron parte fundamental de los diferentes núcleos que conformaron ese hábitat disperso que caracteriza al Castellar de Librilla. Debido precisamente al valor que las pendientes juegan en la configuración de este asentamiento y en los procesos postdeposicionales que se dan en su superficie, interesaba contar con una cartografía adecuada (Fig. 5A) con la que valorar las zonas de ocupación en función de la topografía de su emplazamiento, así como evaluar si la posición de los hallazgos detectados en superficie procedía de entornos inmediatos, o si, por el contrario, habían sufrido desplazamientos considerables en razón de los procesos mecánicos empren$\operatorname{didos}^{6}$.

La metodología seguida corresponde a la propia de la prospección arqueológica intensiva, buscando obtener un registro exhaustivo de la distribución del material y los restos constructivos, así como de sus características y estado de conservación (Mayoral et al. 2009; Brotons et al. 2016; Grau Mira 2016; Ros et al. 2016; Cutillas 2018). El planteamiento de la intervención ha seguido un carácter intensivo a partir de una serie de tracks o recorridos preestablecidos que, en algunos casos, han tenido que adaptarse a la propia morfología de las pendientes (Fig. 5). El equipo de prospección ha estado formado por un total de cuatro prospectores equipados con GPS para georreferenciar las evidencias arqueológicas identificadas y a una distancia variable entre 2,5 y 3 metros, consiguiendo una perspectiva bastante completa de la superficie examinada. Todo ello ha permitido un registro exhaustivo tanto de

En relación a los datos arqueológicos y al mapa de pendientes obtenido, las zonas de mayor densidad de material arqueológico coinciden casi en su totalidad con las zonas de menor pendiente y más adecuadas para el establecimiento de zonas habitadas; únicamente la zona más elevada del S11 y el propio S14 revelan un mayor determinismo de las pendientes, aunque la detección de estructuras in situ permite pensar que el material hallado pertenezca en gran parte a estos sectores. la distribución del material -cronología, características, producciones- como de los restos arquitectónicos visibles en la ladera, pudiendo obtener un mapa de dispersión de los hallazgos y de las zonas sin evidencias a partir de los que plantear los nuevos sectores de ocupación del yacimiento y cálculos de densidad del material mediante programas de información geográfica. La caracterización del material identificado, tanto de aquel seleccionado como del registrado en los cuadernos de campo, ha permitido plantear una determinada adscripción cronocultural a cada uno de los sectores reconocidos, permitiendo su análisis dentro de las dinámicas internas del desarrollo del asentamiento y su implantación poblacional.

\subsection{Resultados}

En el transcurso de la intervención arqueológica desarrollada entre los meses de junio y julio de 2019 se consignaron un total de 1645 waypoints (wp) correspondientes a individuos o concentraciones de material asignados a los dos horizontes arqueológicos identificados en el área de estudio. Por un lado, las evidencias de adscripción al período Bronce Final / Edad del Hierro se han georreferenciado bajo 1575 $w p$ que comprenden un total de 6177 fragmentos cerámicos, 12 molinos barquiformes y de mano, 2 muestras malacológicas y 1 pequeña cuenta de bronce; por otro, se ha constatado la existencia de cerámicas correspondientes a una frecuentación de época moderna y contemporánea, asignando $70 w p$ para 181 fragmentos cerámicos. Centrándonos en el primer horizonte, al que se dedica este estudio, las cifras que se manejan revelan el volumen considerable del material superficial existente en el área total del yacimiento y la amplitud de la ocupación del mismo, circunstancia que debe ponerse en relación con la fuerte erosión natural y antrópica sufrida. Ante la imposibilidad de poder diferenciar con garantías la adscripción precisa a un determinado período cronológico de estos ítems cerámicos, ya que en su mayoría se trata de fragmentos informes, se decidió significar en los cuadernos de campo el tipo de producción al que pertenecían: cerámica a mano bruñida, cerámica a mano de cocina, cerámica gris a torno, cerámica pintada, cerámica de engobe rojo, paredes de ánforas, etc. Esta cuestión, siempre presente en estudios de este tipo, ha sido subsanada parcialmente gracias a la recogida y georreferenciación de 
aquellos individuos que presentaban forma, el $1,50 \%$ del total de los fragmentos del horizonte, y cuyo dibujo y posterior análisis han permitido realizar una aproximación cronológica más precisa.

De esta forma, tras el tratamiento informático y estadístico de los datos se ha podido definir la existencia de hasta 12 nuevas zonas de ocupación en el espacio que abarcaría el asentamiento del Castellar de Libri1la, completando los hasta ahora conocidos 4 sectores propuestos por uno de nosotros (Ros 1989: 92). En total, aunando datos antiguos y recientes, nos encontramos ante un total de 16 sectores de ocupación que amplían la superficie conocida del yacimiento a más de 45 hectáreas de superficie (Fig. 6 y Fig. 7); unas dimensiones sin contar el $\mathrm{Ca}-$ bezo de la Fuente del Murtal y la parte de vega de la rambla de Algeciras que se localiza entre ambos relieves. Aunque los sectores definidos espacialmente sean fundamentales para comprender, como se expondrá a conti- nuación, las dinámicas evolutivas del núcleo gracias al registro material que se ha podido individualizar en cada uno de ellos, el espacio ocupado va más allá de los sectores singularizados ya que el hallazgo de evidencias cerámicas continúa en otros espacios de las zonas altas, medias y bajas, aunque en densidades menores. Esta red urbanística debió proporcionar al Castellar de Librilla una imagen de ciudad de primer orden y especial relevancia, capaz de salvar una accidentada topografía gracias a importantes aterrazamientos a partir de los que construir estructuras de gran envergadura, tal y como sucede en otros núcleos del Sureste como Peña Negra o Santa Catalina del Monte. El estudio singularizado del material arqueológico identificado en cada área y su concentración espacial ha permitido asociar cada sector a una o varias fases de la vida del asentamiento, sustentado la nueva lectura e interpretación arqueológica del Castellar tal y como se refleja a continuación.

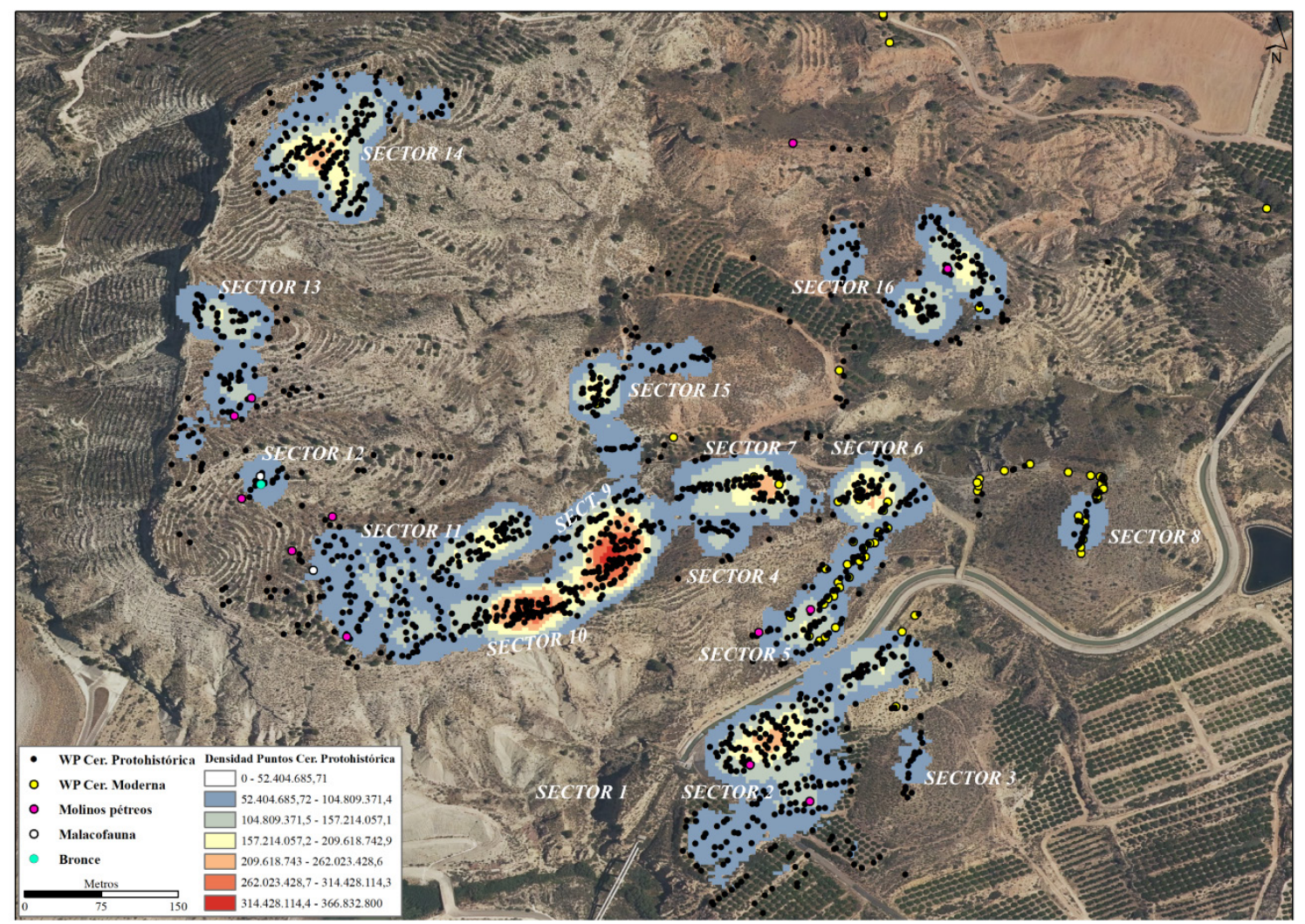

Fig. 6. Distribución espacial de los waypoints marcados durante la prospección arqueológica y análisis de densidad Kernel sobre los puntos correspondientes al Bronce Final y la Edad del Hierro (Elaboración Propia. PNOA - IGN). 


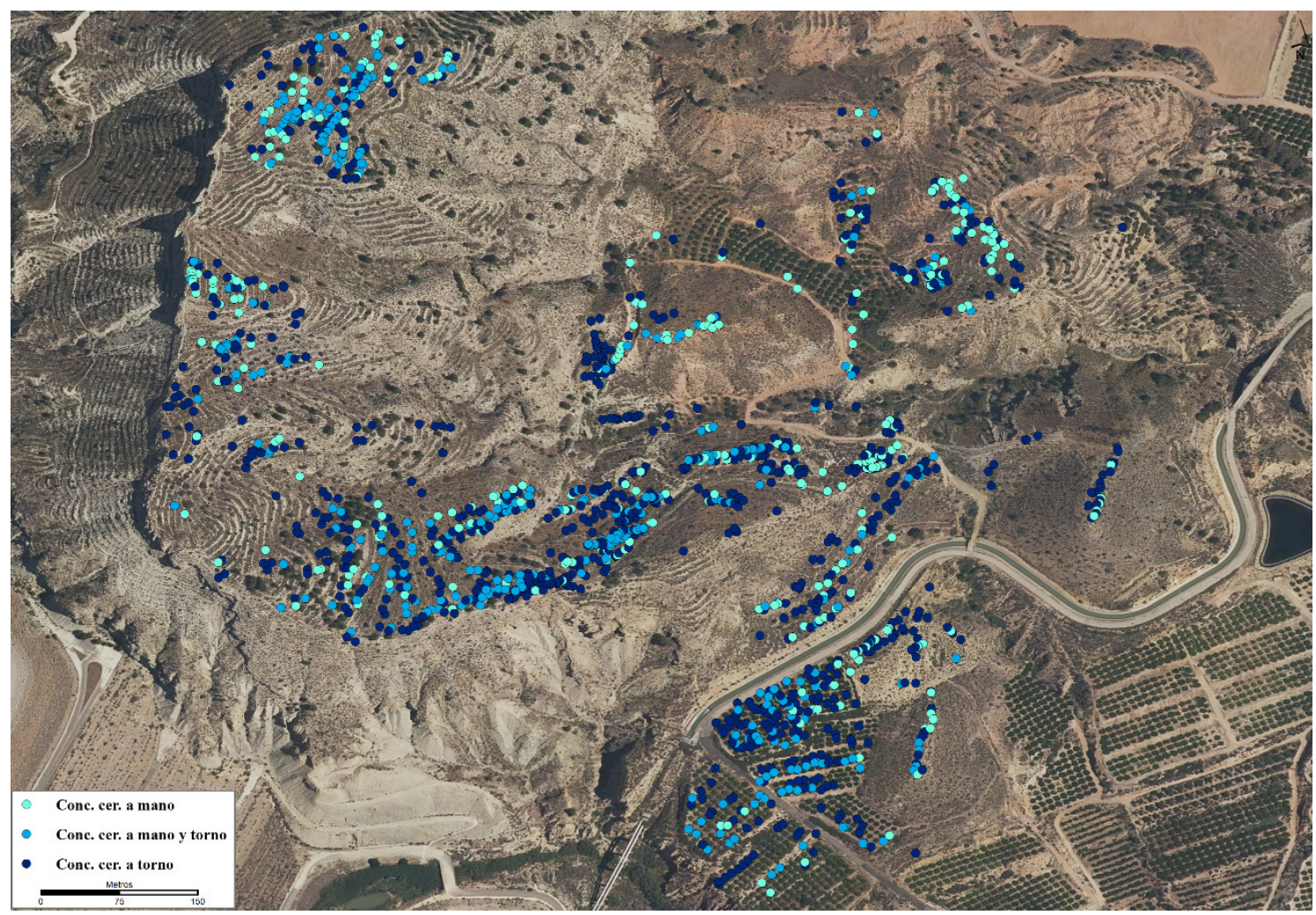

Fig. 7. Distribución espacial de los waypoints cerámicos marcados durante la prospección arqueológica correspondientes al Bronce Final y la Edad del Hierro discriminados por tipo de manufactura (Elaboración Propia. PNOA - IGN).

\section{a) Zona Baja (S1, S2, S3 y S5)}

Estos sectores (S) se localizan en el espacio que se desarrolla en la vertiente sur del Cabezo Basón prolongándose hasta el cerro de Lo Pollo y la rambla de Algeciras. En su día ya fueron definidos por Ros (1989) en tanto que las intervenciones arqueológicas de la Universidad de Murcia se focalizaron en esta área baja debido a la importante afectación que la construcción del canal del trasvase había provocado en el resto de la zona. Las excavaciones desarrolladas desde 1980 se centraron principalmente en el S1, cuya secuencia es la mejor conocida y amplia del complejo, aunque en la última campaña realizada en 1985 se inició un corte junto a la muralla ibérica que ayudó a conocer de forma preliminar el S3 que agrupa las evidencias del cerro de Lo Pollo y que se corresponde con la Fase VI de transición entre el ibérico antiguo y el pleno. En el espacio entre ambos sectores, se localiza una importante extensión de terreno que coincide con S2 bajo el cual se localizaba el asentamiento de parte de la ciudad ibérica (Fig. 8A), aunque por desgracia esta amplia zona y de interés fundamental para este período de formación de la Segunda Edad del Hierro fue roturada con medios mecánicos por el dueño del terreno, destruyendo en gran medida el registro arqueológico existente sin que se pudiese intervenir sobre la misma. No obstante, se localizó en superficie el cierre de la muralla defensiva del asentamiento hasta la misma margen de la rambla.

A pesar de ello, durante las prospecciones arqueológicas se decidió incluir este área con el objetivo de valorar el estado en el que se encontraba la zona, actualmente yerma en una parte y dedicada al cultivo de frutales en otra, y documentar el registro material que permanecía a pesar de la remoción sufrida. En este sentido, se documentaron en el S2 varios perfiles correspondientes a ánforas de la serie T-11 de Ramón, concretamente el tipo T-11.2.3, bordes de ánforas, tinajas y tinajillas ibéricas, platos de borde entrante y abierto con carena o fondos anulares con pie marcado (Fig. 8C). Los tipos son claramente adscribibles a la Fase VI del Castellar y muestran la continuidad del núcleo desde el último cuarto del siglo VI a.C. hasta época ibérica plena. No obstante, también hay algunas formas anteriores interesantes, como el caso de ánforas del tipo T.10.1.2.1 o varias 
bases a mano de fondo plano entre las que destaca una que cuenta con improntas de cestería, un acabado típico del Hierro Antiguo del Sureste ibérico. Antes de su destrucción por el dueño del paraje, su correlación topográfica respecto del S1 implicaba la continuidad habitacional, en mayor o menor medida, de ambos sectores en el momento de expansión que el asentamiento vive especialmente a lo largo del siglo VII y la primera mitad del siglo VI a.C., siendo muy probable su ocupación previa, desde la más antigua conocida e identificada, en su momento, como Fase II.

Un sector que se ha decidido singularizar respecto al mapa original del Castellar ha sido el identificado como Sector 5. Este se corresponde con el espacio bajo que queda entre el recorte que provoca la obra del trasvase Tajo-
Segura y el Cabezo Basón y, aunque puede que parte del material hallado sea producto de la erosión procedente de este último, el gran número de evidencias cerámicas documentadas, la presencia de estructuras in situ y la preservación de su registro arqueológico creemos que permiten definirlo como un sector particular (Fig. 8B). A pesar de que únicamente se ha podido constatar un fragmento de plato con labio vuelto y pendiente con carena exterior, cuya pasta beige amarillenta bien levigada y compacta lo aleja del horizonte del Hierro Antiguo donde esta forma se daba en cerámica gris bruñida o con engobe rojo, probablemente nos encontramos ante la reserva de mayor valor para el futuro conocimiento de esta parte baja de la ciudad que se prolonga de forma intensa hasta el actual camino de entrada al Castellar.
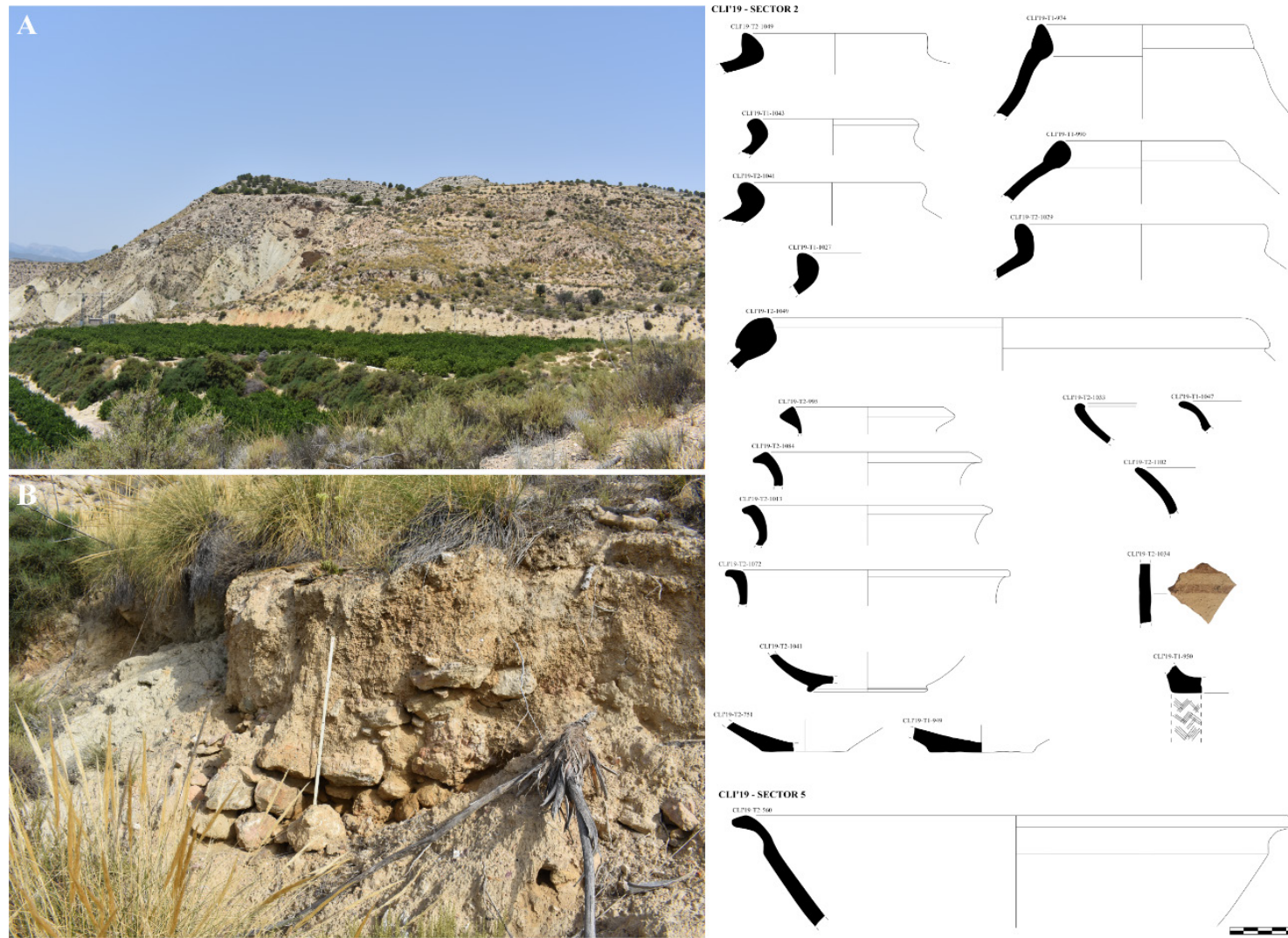

Fig. 8. A. Imagen actual del Sector 2 (en llano) y elevaciones del macizo del Castellar de Librilla desde el Cerro de Lo Pollo; B. Estructuras del Sector 5 visibles en superficie debido a la erosión natural;

C. Materiales arqueológicos correspondientes a los S2 y S5. (Elaboración propia)

b) Zona Intermedia (Sectores S4, S6, S7, S8, S9, S10 y S11)

La ocupación de las elevaciones y terrazas localizadas a media altura del Castellar de Librilla se comprobó a partir de las excavaciones realizadas en la cima del Cabezo Basón, proponién- dose además como la zona en la que se inició la ocupación del yacimiento (Ros 1989: 107). Esta elevación que fue en su día denominada como Sector 4 debe ponerse en relación a su posición dominante sobre su vertiente sur, donde se desarrollarían los sectores expuestos anteriormente, 
pero también tiene que comprenderse en relación a su vertiente norte que hasta hace poco ha sido una zona importante de vaguada que sirve como zona de paso y cultivo gracias a la fuente natural del Castellar (Fig. 9A). En torno a este punto fundamental de surgencia de agua se articulan una serie de sectores importantes de ocupación que destacan por las mayores concentraciones de material del área estudiada (Fig. 9B). Estas se distribuyen tanto en el entorno inmediato de la fuente y las terrazas intermedias próximas que se disponen en el trayecto hacia las cimas de la sierra-Sectores 10 y 11 -, como en las vertientes que se establecen a ambos lados del paleocauce principal que, con origen en la fuente del Castellar, vertebra este sistema geológico -Sectores 6,7 y 9 -

Si bien se trata de sectores en los que no se han localizado restos de estructuras en superficie, en su conjunto la secuencia material es especialmente amplia, tanto a nivel cuantitativo como cualitativo. En cualquiera de estos cinco sectores es habitual la presencia de formas cerámicas correspondientes tanto al Hierro Antiguo como al Ibérico Antiguo, con la presencia de ánforas de las series T10 y T11, formas como los cuencos trípodes junto a formas ibéricas o platos de labio vuelto de cerámica gris bruñida con restos de cerámica pintada ibérica. La adscripción por tanto de esta zona del asentamiento, articulada en torno a la principal captación de agua para el mismo, apunta hacia una notable transversalidad en consonancia con las distintas fases reconocidas en las secuencias cronoestratigráficas de las intervenciones de 1981 a 1986, abarcando desde el siglo VIII al siglo IV a.C. Tanto es así que, entre los materiales documentados, destaca la aparición en el Sector 11 de una fuente carenada de clara adscripción a un Bronce Final Pleno (Fig. 9) cuya cronología se sitúa en el siglo $\mathrm{X}$ o IX a.C. en sintonía con los datos apuntados para otros yacimientos del Sureste ibérico como Coimbra del Barranco Ancho, Caramoro II o el Barranc del Botx (Ros 1990; García Borja et al. 2010: 47; García Borja et al. 2007: 100). Estos datos apuntan a ese primer asentamiento de la comunidad del Castellar sobre el Cabezo Basón planteado por Ros dentro de la Fase I de Librilla (Ros 1989: 111) y las terrazas que se prolongan a su misma altura en la sierra del Castellar. No obstante, existen otras evidencias de una posible ocupación sincrónica en otros puntos del complejo poblacional como apuntan los hallazgos del Sector 16.
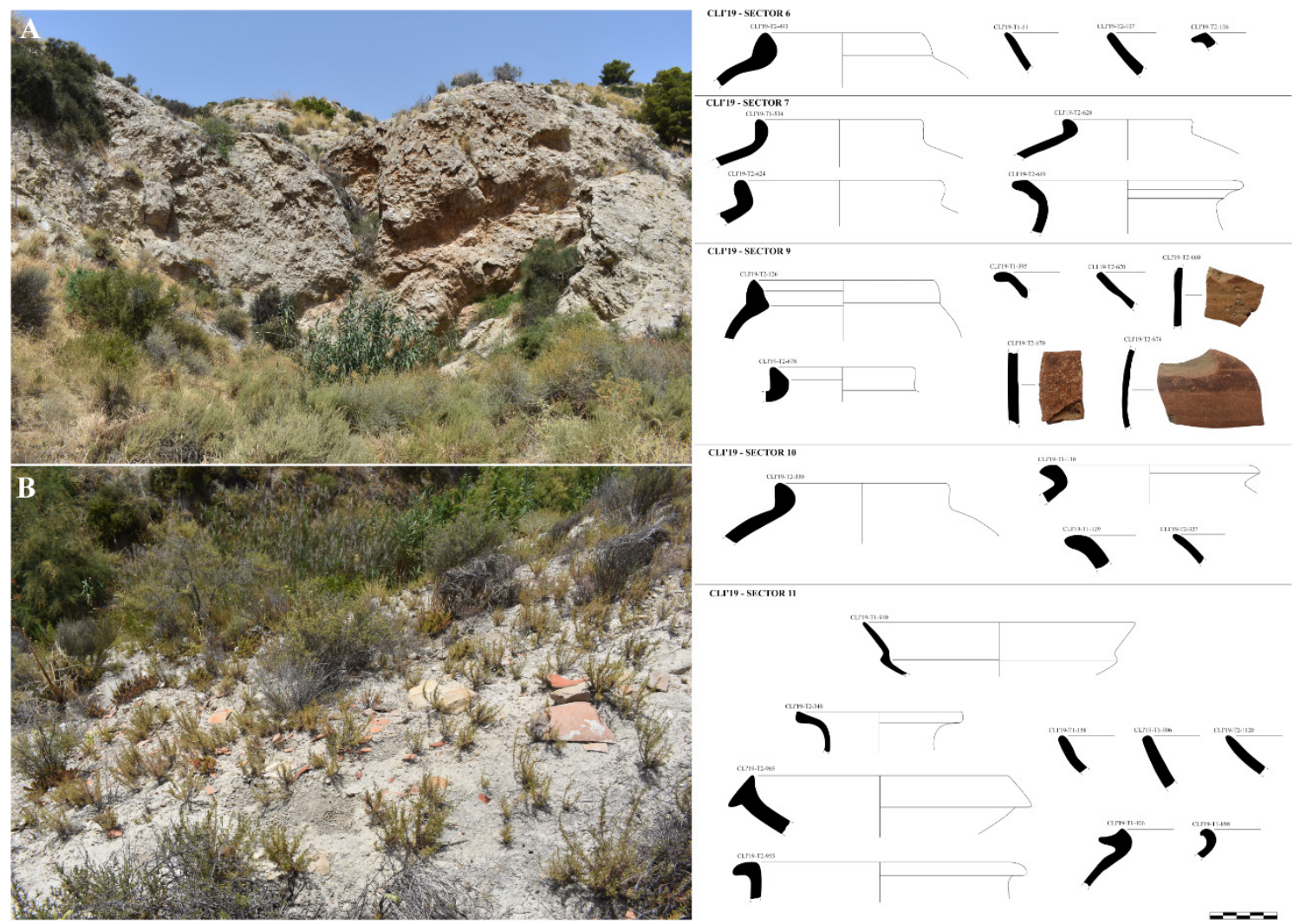

Fig. 9. A. Imagen actual de la Fuente del Castellar; B. Fotografía de detalle del material hallado en las zonas que jalonan el paleocauce procedente de la fuente del Castellar; C. Materiales arqueológicos dibujados correspondientes a los S6, S7, S9, S10 y S11 (Elaboración propia). 
Por último, más alejado hacia el este se encuentra el Sector 8, una suave loma que queda un tanto inconexa del conjunto urbano pero que, como se apuntó en la década de los años 80 y se ha confirmado tras las prospecciones aquí presentadas, también se encontraba claramente ocupada. Sin embargo, el estado de este cerro se ha visto afectado por dos motivos que han mermado el registro arqueológico de su superficie. Por un lado, la construcción de una torre de alta tensión ha modificado parte de la zona norte del mismo, rebajando el nivel de suelo y destruyendo el posible registro arqueológico asociado. Por otro, existe una gran estructura en su cima amesetada a modo de gran corralón o zona para el resguardo de ganado, de construcción contemporánea en consonancia con la mayor concentración de material de tipo moderno/contemporáneo que se ha localizado en el área de estudio. La ausencia de formas impide realizar una aproximación precisa de su ocupación, pero por sus características y su posición es más que probable que esta se prolongara durante el Hierro y el Ibérico Antiguo, especialmente por su valor de control visual del Guadalentín en dirección este y de las rutas que procedieran desde la cuenca baja y media del Segura.

\section{c) Zona Cima (Sectores 12-13-14)}

Las tres cimas amesetadas que forman la parte superior de la sierra del Castellar son aquellas que se están viendo más afectadas por los intensos procesos erosivos y el arrastre de los suelos, lo que ha dejado y continúa dejando al descubierto una serie de estructuras de gran entidad. La identificación de numerosos tramos de lienzos constructivos y los indicios iniciales de la existencia de una serie de sectores habitados y desconocidos hasta la fecha motivaron el inicio de esta campaña de prospección arqueológica intensiva. Tras el trabajo de campo y el posterior procesamiento de los datos obtenidos, estos sectores se han revelado como partes esenciales del asentamiento, fundamentales para la comprensión urbanística de las dinámicas de movilidad intra-site y de control territorial del mismo. Su localización en las cumbres del macizo del Castellar, con una diferencia de más de 150 metros de altura relativa entre la posición en la que se encuentra la fuente y la cota superior del Sector 13, pone en evidencia el inestimable valor y el importante esfuerzo que supuso organizar y desarrollar urbanísticamente las edificaciones aquí construidas. La principal característica de la ocupación sobre estas cimas amesetadas es el control visual que permiten de toda el área de la cuenca media del Segura, tanto en en lo que respecta al valle del Guadalentín al sur, como del tramo medio del Segura y su conexión con la rambla Salada y los cauces fluviales de los ríos Pliego y Mula, convirtiéndose en un espacio de referencia territorial y probablemente política en relación al poder establecido en el asentamiento.

Si bien en el caso del Sector 14 no se han detectado estructuras visibles en superficie a pesar de la alta concentración de material cerámico a mano y a torno identificado, seguramente debido a la elevada alteración postdeposicional de la zona por los trabajos de reforestación, la situación en el Sector 13 es completamente distinta. Los procesos erosivos han dejado al descubierto una cantidad excepcional de estructuras en las dos cimas centrales del sistema que se corresponden con espacios de hábitat $\mathrm{y}$, especialmente, una serie de lienzos de fortificación de gran envergadura dotados de salientes que configuraron probables torreones en líneas de fortificación. La entidad de estos tramos amurallados, compuestos por un aparejo de piedra seca con piedras trabadas de tamaño medio y grande, se revela en sus dimensiones; algunos de los lienzos documentados en la parte este del Sector 13 son visibles a lo largo de tramos que alcanzan los 20 y 40 metros de longitud (Fig. 10 A y Fig. 11A-D). Su distribución espacial apunta a recorridos mayores y perfectamente conectados que conformaron auténticos cordones fortificados, mientras en su parte norte los barrancos verticales del propio relieve hacen inexpugnable la cumbre como defensa natural. Sin embargo, el hallazgo en las terrazas inferiores de otras estructuras y abundante material arqueológico de tipo cerámico, malacológico o, incluso, de una cuenta de bronce en el Sector 12, revela que la ocupación de esta parte alta de la ciudad no solo se centraría en estos recintos fuertemente fortificados, sino que mediante la adecuación de las laderas de fuerte pendiente a partir de un notable sistema de aterrazamiento sería posible la ocupación de estos espacios. 


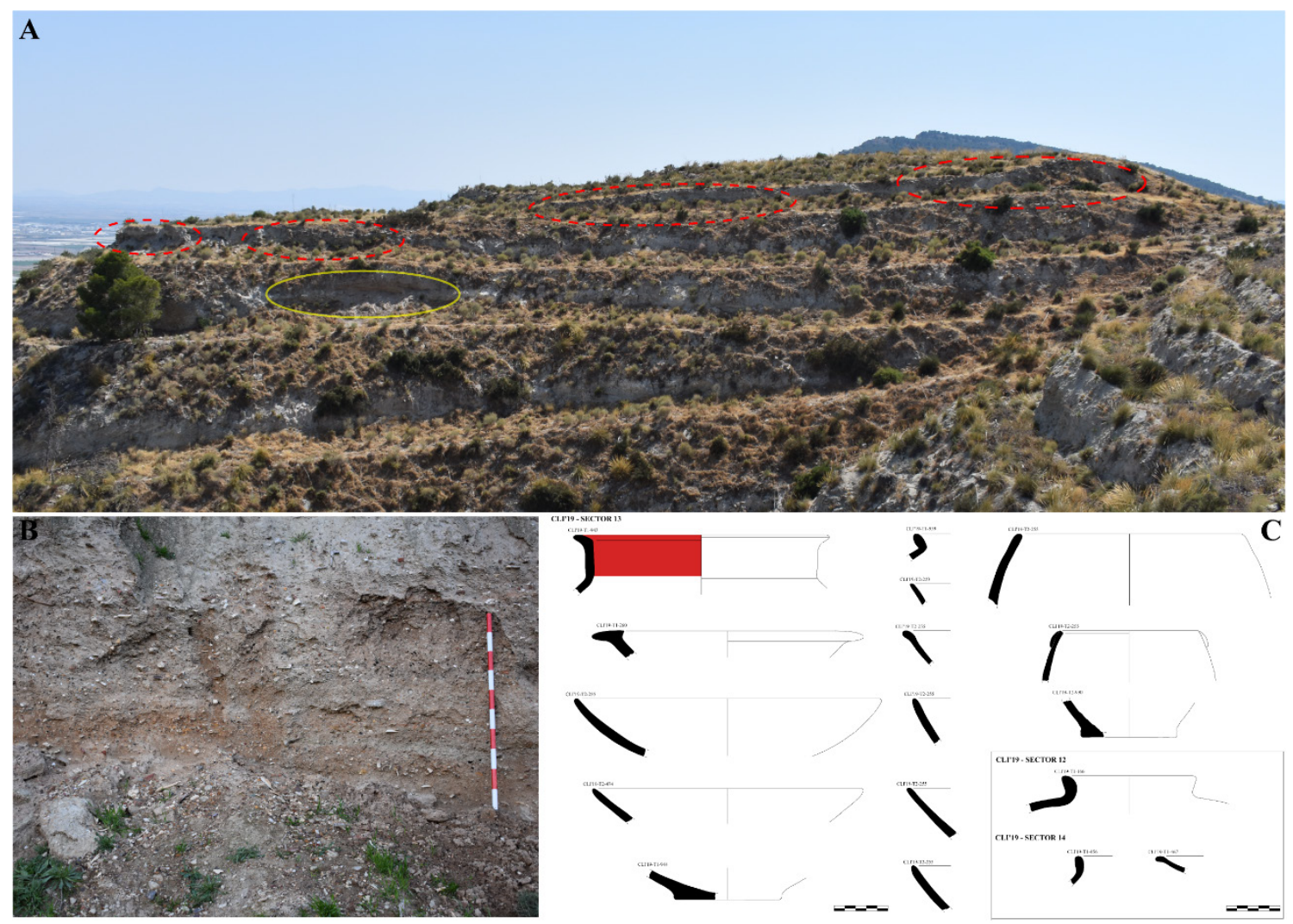

Fig. 10. A. Imagen del flanco este del Sector 13 en el que se aprecian las diversas estructuras fortificadas en rojo y las dimensiones del basurero de la acrópolis en amarillo; B. Detalle del basurero; C. Materiales arqueológicos correspondientes a los S12, S13 y S14. (Elaboración propia).

Tal disposición urbanística proporcionaría una imagen de denso poblamiento en estas partes altas del complejo que, concretamente en el Sector 13, correspondería con un espacio singularizado y fuertemente fortificado coincidente con el punto más elevado de la ciudad. La amplia ocupación de este sector, además, se ve confirmada por el hallazgo en una de las terrazas inmediatamente inferiores a un tramo fortificado del Sector 13 de un potente basurero cuyas dimensiones alcanzan, al menos, ocho metros de longitud y un metro de profundidad (Fig. 10B). Esta enorme potencia muestra el uso prolongado de esta zona fortificada y su futura intervención revelará una información ingente sobre los modos de vida de la comunidad que habitó este sector ya que en su perfil se aprecian restos de tipo faunístico, malacológico, cerámico, botánico, etc. Pero, quizás, los datos más interesantes para entender las diferentes etapas de este asentamiento principal del Sureste ibérico se obtienen de los materiales cerámicos hallados. Las evidencias documentadas en estos sectores 12,13 y 14 delimitan una ocupación concentrada en un pe- ríodo sincrónico a las fases Castellar III y IVa, es decir, a lo largo del siglo VII y la primera mitad del siglo VI a.C. Entre el ajuar cerámico localizado (Fig. 10C) destacan las formas cerradas de cocina a mano, la presencia de platos en cerámica gris bruñida con labio vuelto o sin labio, un plato de ala vuelta indicado al interior de engobe rojo, ánforas del tipo T.10 idénticas a las descritas bajo el tipo VIII.P.4 y VIII.P.5 de Ros (1989: 285) y dentro del Tipo 1 de Fonteta VI (González Prats 2011: 357 y 361); y un pithos que se encuadra dentro de las variantes V.K definidas por Ros para el asentamiento (1989: 268-272) con paralelos en Los Saladares I-B1 y I-B2 (Arteaga y Serna 1975: Láms. 11 y 17), Peña Negra II (González Prats 1990: 243-244, Figs. 15 y 16) o Fonteta IV y V (Pla 2014: 700, Fig. 7).

La potencia de las construcciones y los datos obtenidos tras la prospección superficial permite entrever una interesante cuestión que debe quedar por el momento abierta sobre el significado de estas estructuras del Sector 13, plenamente insertadas en el tejido urbano del asentamiento, pero delimi- 
tando con claridad un espacio diferenciado a nivel espacial y paisajístico volcado al control territorial inmediato. Podría tratarse, por un lado, de un espacio destinado al establecimiento de los grupos dominantes del asentamiento a modo de acrópolis, tal y como sucede con lo planteado en el Sector III de Peña Negra (Lorrio et al. 2016: 39); o bien, por otro lado, que estemos ante un establecimiento defensivo tipo fortín que aprovecha un punto ideal para su cometido.
En cualquier caso, la ausencia de formas correspondientes al ibérico antiguo, ni siquiera en los fragmentos informes identificados en el transcurso de la actuación, apunta al claro abandono de estos sectores en altura y al definitivo colapso de las estructuras en un momento correspondiente a la segunda mitad del siglo VI a.C. y dentro de las profundas dinámicas de reestructuración territorial que marcaran la transición entre el horizonte cultural del Hierro al Ibérico Antiguo.
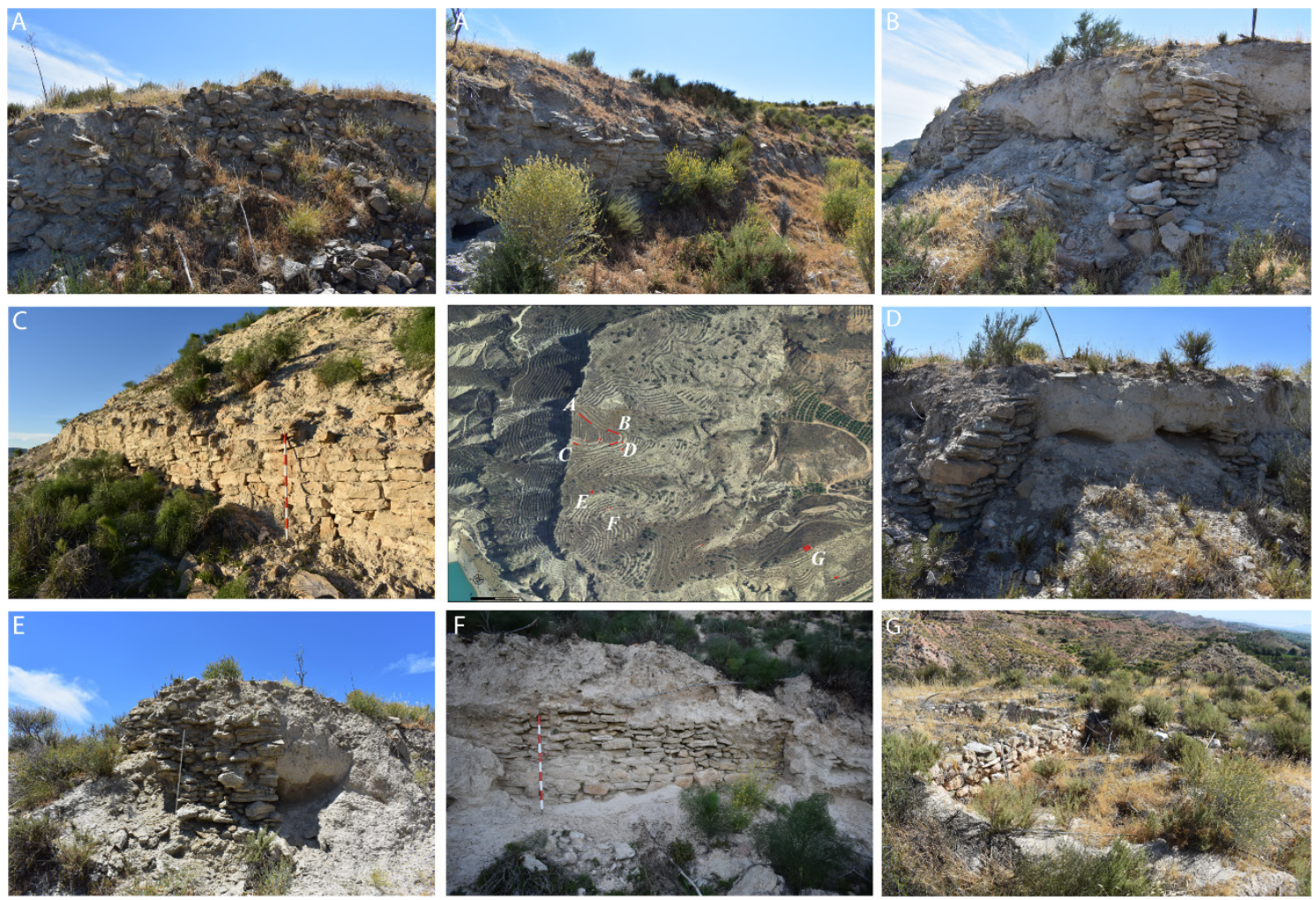

Fig. 11. Distribución espacial e imágenes de detalle de las diferentes construcciones identificadas en las cumbres del Castellar de Librilla (Imágenes de los autores. PNOA - IGN).

\section{d) Zona Norte (Sectores 15-16)}

Utilizando como línea divisoria el antiguo curso de la fuente del Castellar, al norte de su cauce se han identificado concentraciones importantes de evidencias arqueológicas en varias elevaciones que no hacen sino ampliar y diversificar el espacio habitado de la ciudad. Su posición indica la importancia que esta vertiente norte juega en el paisaje y en la configuración urbanística del núcleo, especialmente como marcador de los límites del asentamiento en sus diferentes etapas. Comenzando por el Sector 15 , se trata de un cerro con una densidad importante de material (Fig. 12A) cuya presencia se prolonga desde su cima hasta la ladera meridional de la sierra del Castellar, lo que evidencia un poblamiento de la zona importante $\mathrm{y}$, como muestra el análisis cerámico, prolongado en el tiempo. La existencia de ánforas de la serie T10.1.2.1 y T11.2.1.3, junto a platos de cerámica gris y tinajillas ibéricas, revela la pervivencia de este sector desde, como mínimo, el siglo VII a.C. hasta el V a.C., participando activamente de los diferentes movimientos de expansión urbanística a lo largo de las fases III y IV de ocupación del Castellar.

Más revelador es la información del Sector 16, el más alejado del a priori núcleo urbano y que, a la luz de los datos obtenidos, se presenta como una zona de denso poblamiento que simboliza a la perfección ese urbanismo disperso, quizás intencionado por razones funcionales, 
que se da entre algunos de los núcleos de primer orden en esta primera mitad del I milenio a.C. en el Sureste. Pero lo más interesante respecto a este sector es que los datos obtenidos apuntan a una ocupación antigua de la zona, concretamente durante el Hierro Antiguo, al igual que sucedía en los sectores detectados en la cima, y con probable inicio en el Bronce Final. La presencia de una fuente bruñida a mano y de carena media (Fig.12C) presente en contextos de Peña Negra I (González Prats 1990: 266-267) y Los Saladares I-A1 y I-A2 (Arteaga y Serna 1975: Lám. II) así parece atestiguarlo, formando parte de ese horizonte inicial todavía difuso para el asentamiento, pero cada vez mejor conocido con las evidencias del Sector 4 y Sector 11. El resto de tipos son propios de los siglos VII y la primera mitad del siglo VI a.C., con ánforas correspondientes a la serie $\mathrm{T}-10.1 .2 .1$, platos de cerámica gris sin labio y bases planas, o fondos con talón suavemente indicado correspondiente a tipos de almacenaje y cocina a mano. El abandono de este sector en un momento paralelo al de los Sectores 12, 13 y 14 es un síntoma más de la contracción urbanística de la comunidad del Castellar y se constituyen en un claro ejemplo de las micromovilidades asociadas a la coyuntura de transición que tiene lugar en la segunda mitad del siglo VI a.C. (Ros 1989).
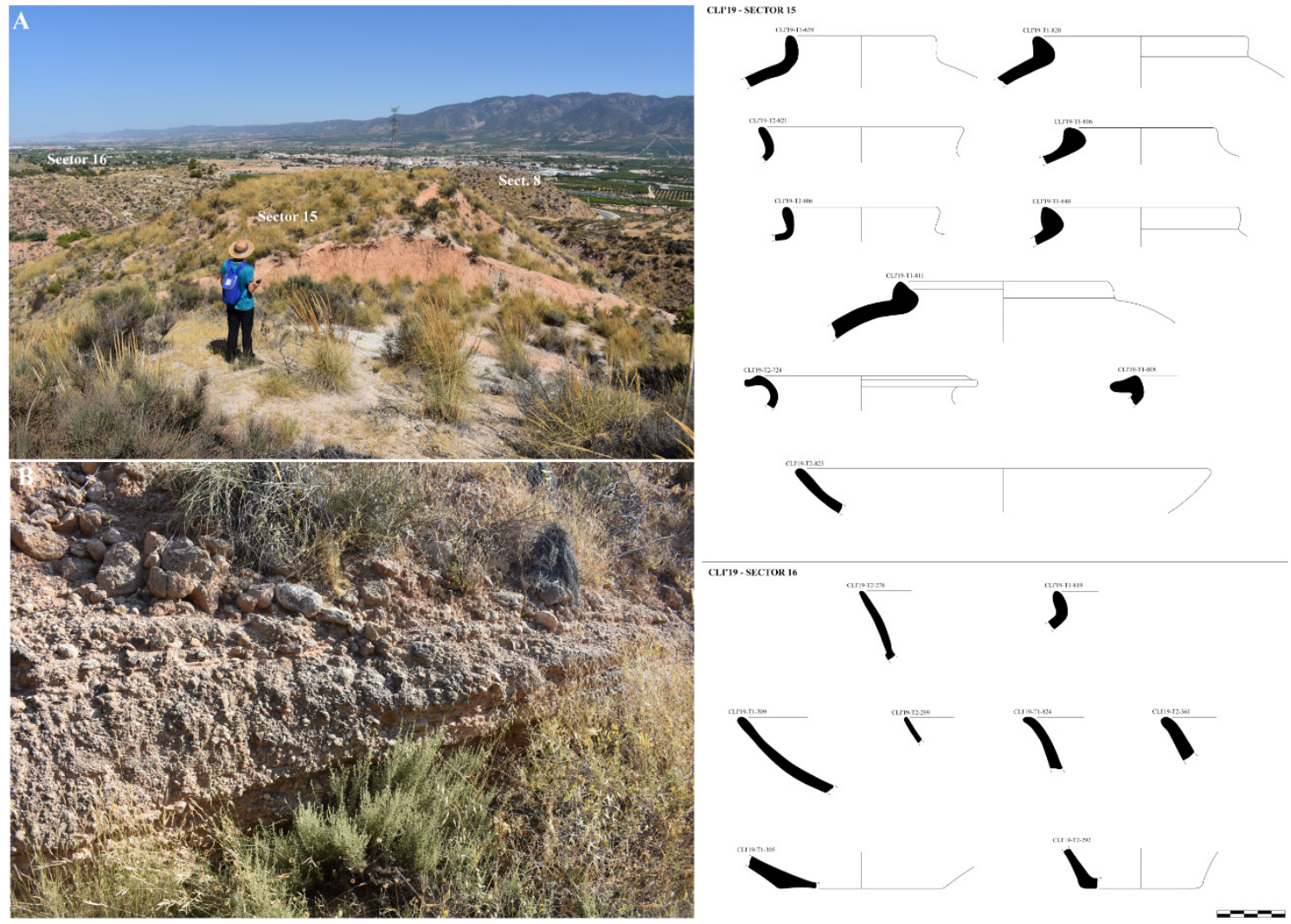

Fig. 12. A. Distribución espacial de los Sectores identificados al norte del paleocauce durante la prospección arqueológica intensiva; B. Detalle de los estratos geológicos correspondientes al paleocauce procedente de la fuente del Castellar; C. Materiales arqueológicos correspondientes a los S15 y S16 (Elaboración propia).

\section{Reajuste poblacional y evolución intra-site: del Bronce Final reciente al período ibérico en el Castellar de Librilla}

Los datos actuales, tanto procedentes de las excavaciones arqueológicas como de la reciente prospección, apuntan a una fundación del asentamiento del Castellar de Librilla en el siglo IX a.C., dentro de las dinámicas propias del Bronce Final reciente a partir de las cuales se produce una importante reestructuración de los paisajes y territorios del Sureste ibérico. Al igual que sucede en Peña Negra, Santa Ana o Los Saladares, se sientan las bases de unos núcleos que se caracterizarán por una importante perduración en el tiempo gracias a las 
características geoestratégicas y productivas de sus emplazamientos, intensificando y diversificando el poblamiento coetáneo dependiente de núcleos permanentes como Lorca o Santa Catalina del Monte. En cuanto al Castellar, parece claro que se pone en práctica un patrón de ocupación de diversas zonas elevadas y en torno al punto que vertebra este poblamiento, la imponente surgencia del Castellar. De ahí que se produzca una primera ocupación temprana del Cabezo Basón y algunas de las terrazas intermedias de la sierra del Castellar-Sector 11ligadas a la proximidad al cauce de la rambla de Algeciras. No obstante, la información procedente del Sector 16 aborda la existencia de un hábitat que ya desde sus inicios se gesta en el marco de un modelo polinuclear de carácter disperso a pesar de situarse en un mismo entorno geográfico y bajo la misma organización sociopolítica. La orientación de ambos sectores se pone exclusivamente en relación con el cauce del Guadalentín, sobre el que cuentan con un amplio dominio visual, y desde zonas elevadas fácilmente defendibles gracias a los escarpes naturales con los que cuentan.

Con el siglo VIII a.C. se produce la definitiva entrada y consolidación de las posiciones fenicio-occidentales en los circuitos comerciales litorales de la región (López Castro et al. 1987-1988; Rouillard et al. 2007; González Prats (ed.) 2011; García y Prados 2014; Ros 2017), lo que incrementó de forma significativa las actividades productivas y el establecimiento de relaciones estables entre los asentamientos autóctonos y los entornos coloniales. La intensificación de estas relaciones ligadas a las transacciones de materias primas y productos elaborados igualmente evidenciadas en El Castellar (Ros 1989), inauguró un importante período de auge demográfico y urbanístico durante el siglo VII y la primera mitad del siglo VI a.C. que se vio reflejado en una tendencia de expansión de los núcleos de primer orden de la región. En el marco de este proceso, las ciudades autóctonas se dotan de importantes cinturones defensivos y de espacios singulares también fortificados dedicados a simbolizar el poder de las jefaturas de cada comunidad, lo que cristaliza el poder que estas llegan a alcanzar al ser capaces de movilizar importantes fuerzas de trabajo para la edificación de sus acrópolis o fortines, y la creciente desigualdad social que se intensifica en períodos de bonanza; pero también se amplía el objetivo económico e ideológico de estos núcleos hacia espa- cios controlados y a territorios políticamente diversos con los que las relaciones interterritoriales adquieren una perspectiva económica sobresaliente $\mathrm{y}$, por ende, de vigilancia permanente. El período de máxima extensión del espacio ocupado en el Castellar, con todos los sectores habitados y una primera instalación en el Cabezo de la Fuente del Murtal, aunque conocida de forma residual, coincide con la expansión del territorio productivo propio, la intensificación en las relaciones económicas y comerciales, y el inicio de los trabajos de construcción de las estructuras identificadas en el Sector 13; una coyuntura a todas luces favorable a partir de la cual el asentamiento del Castellar se dotó de una imagen de núcleo de poder para la región muy similar a la presentada en Peña Negra (González Prats 1983; Lorrio et al. 2016) y coincidente en el tiempo con la remodelación y expansión urbana de Santa Catalina del Monte, perfectamente representada con las obras ejecutadas para aterrazar la ladera ocupada durante el siglo VII a.C. y la reestructuración generalizada que sufren las viviendas a inicios del siglo VI a.C. (Ros 1986-1987).

La importancia que cobran las estructuras defensivas durante este período deja patente que la presencia de tensiones territoriales entre asentamientos tuvo que ser una constante, especialmente a partir del siglo VI a.C. cuando se detecta en el asentamiento colonial de Fonteta la edificación de una sólida muralla (Rouillard et al. 2007: 126; González Prats 2011: 23) y en el complejo poblacional de la rambla de Algeciras se inicia la construcción de la fortificación del Cabezo de la Fuente del Murtal. En un momento de expansión de este tipo de fortines, como sucede en el territorio de Peña Negra con Les Barricaes y El Cantal de la Campana (Trelis y Molina 2017), la aparición de una estructura con esta envergadura, cerrando el flanco oeste de la ciudad y en un punto más bajo que las fortificaciones de las cimas, pone en evidencia esta necesidad. No obstante, es en el segundo o tercer cuarto del siglo VI a.C. cuando se inicia un intenso proceso de contracción del espacio ocupado en el que la primera consecuencia directa es el abandono de las cimas del Castellar, concretamente de los Sectores 12, 13 y 14, y, poco después, el del Cabezo de la Fuente del Murtal tras una ocupación no muy prolongada. El abandono de áreas, cuya función principal además de la defensiva era la proyección del poder del asentamiento a su entorno próximo, tanto en su orientación hacia el Guadalentín 
como hacia el norte de su posición, supone un punto de inflexión para la propia idiosincrasia del núcleo y se encuentra en consonancia con un momento de disminución demográfica del asentamiento. Este proceso no se produce de manera exclusiva para el asentamiento de la rambla de Algeciras, sino que se desarrolla de
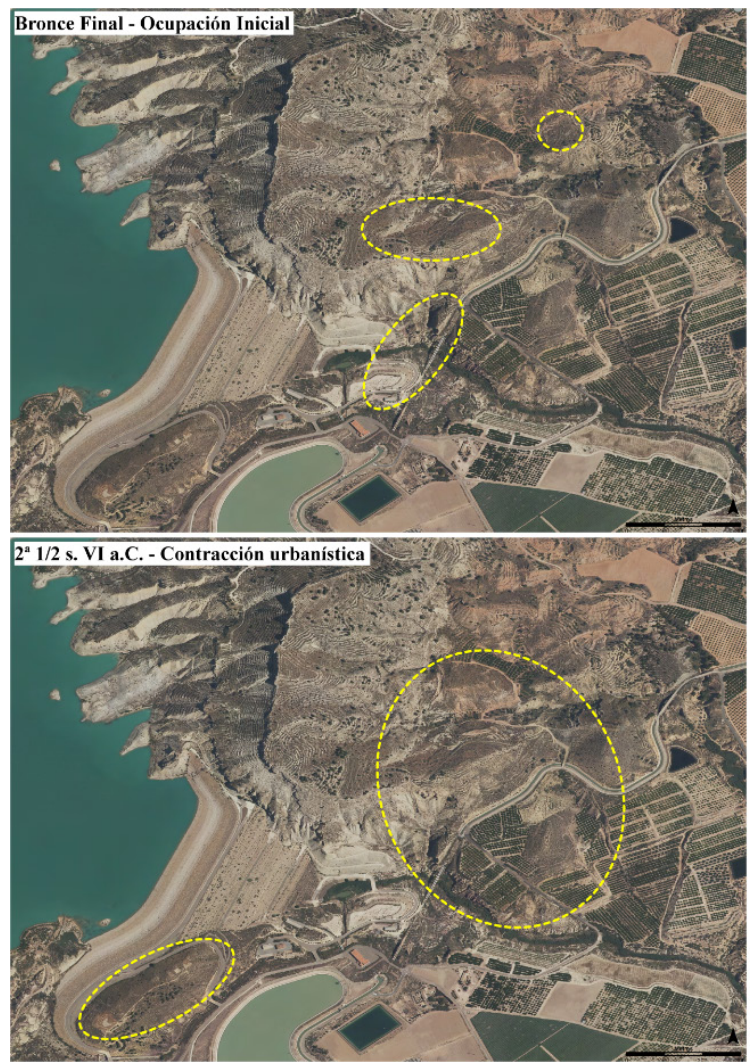

forma general en todo el Sureste, con el abandono de Peña Negra y gran parte de los núcleos rurales de la cuenca prelitoral, así como el desdibujamiento del comercio fenicio en la zona con el abandono progresivo de Fonteta y el menor dinamismo del entorno colonial de la Bahía de Mazarrón.
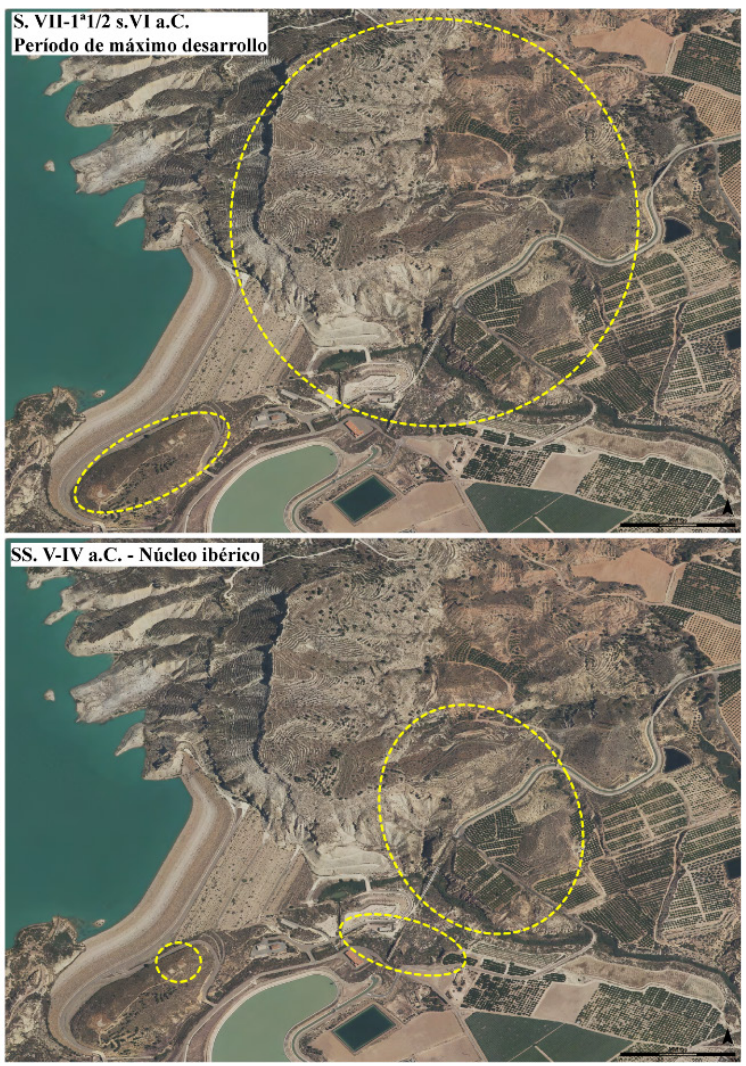

Fig. 13. Propuesta de evolución poblacional del complejo poblacional del Castellar de Librilla (Elaboración de los autores. MDT - IGN)

Sin embargo, a pesar de que también en el Sector 1 tiene lugar el abandono de algunas casas como las BG y K-2 en esa fase Librilla V datada a finales del siglo VI e inicios del siglo V a.C. (Ros 1989), el barrio artesanal continúa en activo y las evidencias cerámicas del Ibérico Antiguo perviven en los sectores cercanos a la fuente del Castellar y las alturas intermedias. No será hasta el período siguiente, con la fase Librilla VI, cuando se produce el abandono de los hornos metalúrgicos y alfarero, la reocupación de este espacio con la construcción de nuevas viviendas ordenadas en una trama que cuenta con espacios dedicados a calles pavimentadas y la construcción de un nuevo sistema defensivo que aprovecha la elevación del Cerro de Lo Pollo para proteger el espacio del núcleo ibérico localizado en la parte baja del relieve (Ros 1989: 155). Este nuevo fenómeno urbanístico se adscribe al horizonte Ibérico Antiguo como denota la presencia constante de materiales anfóricos de los tipos T-11.2.1.3 en esta fase -incluidos dentro del tipo VIII.P.11-, a la cual además creemos que se puede asociar la construcción de la muralla del Sector 3 debido a que, aunque el registro material sea deficitario ante la interrupción de las excavaciones por el arrasamiento de parte del asentamiento, las técnicas constructivas de las casas que se adosan al interior de la muralla no difieren de las documentadas en las casas construidas en esta última fase documentada en el Castellar que alcanza el siglo IV a.C. (Ros 1989: 162).

De esta manera, la reestructuración del núcleo se realizaría en un sentido unitario mediante el que se abandonan las cimas del re- 
lieve para asentarse y fortificar un espacio más accesible al terreno productivo inmediato y a la fuente del Castellar. No obstante, este movimiento no implicó el abandono completo de las alturas anexas, como se ha podido detectar en el Cabezo Basón y la ladera media de la sierra del Castellar, con un importante volumen de materiales adscritos al Ibérico Antiguo. No obstante, el asentamiento, una vez más, no se constreñiría exclusivamente a este margen de la rambla, sino que a esta fase corresponden parte de las estructuras detectadas en la cima NE del Cabezo de la Fuente del Murtal, lo que implica la continuidad de un núcleo que, tras sufrir una importante transformación urbanística y con diversos procesos de micromovilidad interna, continúa ejerciendo su poder sobre su territorio inmediato en una muestra de la resiliencia ejercida por esta comunidad. Un fenómeno de continuidad que se expande desde el Bronce Final hasta el Ibérico Pleno que también parece que se dio en otros asentamientos principales de la cuenca como Peña Negra y Santa Catalina del Monte, lo que evidencia un desarrollo común entre aquellos núcleos que se encontraban bajo el mismo paradigma cultural que evoluciona desde sus fundaciones durante el Bronce Final reciente.

\section{Consideraciones finales}

Las investigaciones recientes desarrolladas en los últimos años sobre el Complejo Arqueológico de la Rambla de Algeciras (Cutillas 2019) han vuelto a poner de manifiesto la importancia que los entornos autóctonos alcanzaron durante el I milenio a.C. La prospección arqueológica practicada en 2019, iniciada como una necesidad real ante el estado de deterioro progresivo que están sufriendo parte de las estructuras identificadas, ha permitido ir más allá del conocimiento que tenemos sobre este tipo de grandes asentamientos polinucleares entre los que sobresale el Castellar de Librilla. Junto a Peña Negra, se trata con probabilidad del núcleo más importante de este sector central del Sureste ibérico, aunque en este caso concreto se debe destacar que estamos ante un asentamiento que no se encuentra en una posición inmediata a un entorno colonial, lo que permite una aproximación menos condicionada a las dinámicas de desarrollo territorial y material que experimentaron estas comunidades autóctonas situadas en el área prelitoral.
La nueva lectura realizada en torno al asentamiento del Castellar de Librilla revela la complejidad en su dinámica interna de desarrollo, especialmente al no ser un núcleo de distribución compacta, sino dispersa en razón a los condicionantes de su propia orogenia y que cuenta bajo su órbita con sectores alejados como el Cabezo de la Fuente del Murtal, parte esencial para la comprensión de la evolución de la ciudad. A partir de los datos todavía preliminares sobre su ocupación durante el Bronce Final reciente, se han podido restituir las intensas transformaciones espaciales y urbanísticas que se desarrollaron en este núcleo durante el Hierro Antiguo y que estuvieron dirigidas por las jefaturas del asentamiento con el objetivo de mantener su control y proyección territorial sobre esta parte de la cuenca del Guadalentín. No obstante, este escenario no solo es clave para comprender los mecanismos de contacto e hibridación cultural que se produjeron en el Sureste ibérico durante esta cronología y que afectaron tanto a los propios sistemas autóctonos como a las comunidades coloniales, sino que la investigación sobre el desarrollo de esta coyuntura es fundamental para comprender la gestación de los oppida ibéricos y la configuración de estos territorios durante la Segunda Edad del Hierro, tal y como ocurre en otras regiones limítrofes mejor conocidas como el Alto Segura y el Alto Guadalquivir.

En este sentido, el análisis realizado a nivel meso espacial de la situación que la ciudad del Castellar de Librilla experimenta a finales del siglo VI y en el siglo $\mathrm{V}$ a.C. difiere a la de un asentamiento en crisis y en proceso de desmantelamiento. Sin negar las profundas reestructuraciones urbanísticas emprendidas y más dirigido hacia la cuenca prelitoral ante la pérdida de las posiciones permanentes en las cimas del relieve, estamos ante los cambios y continuidades de una comunidad que mantiene su estatus y su poder, producto de una realidad de intenso encuentro intercultural. El resultado de este largo proceso no es otro que la configuración de un nuevo oppidum, ahora dentro de unos cánones culturales que han sido identificados bajo el prisma de los grupos culturales ibéricos, pero cuya raigambre perdura en un territorio que se mantiene ocupado de forma continua a pesar de sus épocas de auge y crisis profunda gracias a la resiliencia demostrada por parte de la comunidad que en este espacio habitaba. 


\section{Bibliografía}

Abad Casal, L.; Sala Sellés, F. (2001): Poblamiento ibérico en el Bajo Segura. El Oral (II) y La Escuera. Real Academia de la Historia, Madrid.

Arana Castillo, R.; Pérez Sirvent, M.C. (1993): El trabajo del hierro en el poblado protohistórico de El Castellar de Librilla (Murcia). II: estudio mineralógico. En S.F. Ramallo; A.M. Muñoz; M.M. Ros; R. Arana (coords.), Metalurgia en la Península Ibérica durante el primer milenio a.C.: estado actual de la investigación. Publicaciones Universidad de Murcia, Murcia: 111-130.

Arteaga Matute, O.; Serna González, A. (1975): Los Saladares-71. Noticiario Arqueológico Hispánico, 3: $7-140$.

Bellón Aguilera, J.; Martínez Martínez, C. (2011): Supervisión Arqueológica Preventiva C/Cúspide, La Alberca. Informe inédito depositado en la CARM.

Brotons Yagüe, F.; Ramallo, S.F.; Sanz, R. (2016): El proyecto de recuperación patrimonial del Cerro de los Santos (Montealegre del Castillo, Albacete). En B. Gamo y R. Sanz (coords.), I Reunión Científica de Arqueología de Albacete. Instituto de Estudios Albacetenses Don Juan Manuel, Albacete: 555-568.

Calmel-Avila, M. (2000): Procesos hídricos holocenos en el Bajo Guadalentín (Murcia, España), Cuaternario y Geomorfología, 14 (3-4): 65-78.

Calmel-Avila, M. (2002): The Librilla rambla, an example of morphogenetic crisis in the Holocene (Murcia, Spain), Quaternary International, 93-94: 101-108.

Carrión, J.; Fierro, E.; Ros Sala, M.; Munuera, M.; Fernández, F.; Ochando, J.; Amorós, G.; Navarro, F.; Rodríguez-Estrella, T.; Manzano, S.; González-Sampériz, P.; Moreno, A. (2018): Ancient forests in European drylands: Holocene palaeoecological record of Mazarrón, south-eastern Spain, Proceedings of the Geologist' Association, 129: 512-525. https://doi.org/10.1016/j.pgeola.2018.05.007

Comino Comino, A.; Tortosa Rocamora, T. (2017): Del pretexto al contexto: el santuario de La Luz (Verdolay, Murcia). Nuevas reflexiones para el debate. En S.F. Ramallo y T. Tortosa (eds.), El tiempo final de los santuarios ibéricos en los procesos de impacto y consolidación del mundo romano. Ed. CSIC, Madrid: 135-160.

Contreras Cortés, F. (1982): Una aproximación a la urbanística del Bronce Final en la Alta Andalucía: El Cerro de Cabezuelos (Úbeda, Jaén), Cuadernos de Prehistoria de la Universidad de Granada, 7: $307-$ 329.

Cutillas Victoria, B. (2018): En busca de los pobladores de la Primera Edad del Hierro en el Campo de Cartagena: resultados preliminares en torno a la ocupación del Cabezo Ventura (Sureste ibérico). Lucentum, 37: 75-91.https://doi.org/10.14198/LVCENTVM2018.37.04

Cutillas Victoria, B. (2019): Nuevas investigaciones de la Prehistoria Reciente en el complejo arqueológico de la Rambla de Algeciras (Alhama de Murcia / Librilla): perspectivas, trabajos y revalorización. En XXV Jornadas de Patrimonio Cultural Región de Murcia. Tres Fronteras, Murcia: 139-146.

Dietler, M. (2009): Colonial encounters in Iberia and the Western Mediterranean: an explanatory framework. En M. Dietler; C. López-Ruiz (eds.), Colonial encounters in ancient Iberia: Phoenician, Greek, and indigenous relations. University of Chicago Press, Chicago: 3-48.

Dorado Alejos, A.; Molina González, F.; Contreras Cortés, F.; Nájera Colino, T.; Carrión Méndez, F.; Sáez Pérez, L.; de la Torre Peña, F.; Gámiz Caro, J. (2015): El Cerro de Cabezuelos (Jódar, Jaén): un asentamiento del Bronce Final en el Alto Guadalquivir. Cuadernos de Prehistoria y Arqueología de la Universidad de Granada, 25: 257-347.

García Blánquez, L.A. (1996): El Cerro de la Fuente del Murtal, Alhama de Murcia (1ª campaña 1991): poblado fortificado del período de transición Bronce Final / Hierro Antiguo en el eje de poblamiento Segura-Guadalentín (Murcia). Memorias de Arqueología, 5: 65-85.

García Borja, P.; Carrión Marco, Y.; Collado Beneyto, I.; Montero Ruiz, I.; Muñoz Abril, M.; Pérez Jordá, G.; Roldán García, C.; Roman Monroig, D.; Tormo Cuñat, C.; Verdasco Cebrián, C.; Vives-Ferrándiz, J. (2010): Campaña de excavación arqueológica de urgencia en Caramoro II (Elx, Alacant). MARQ. Arqueología y Museos 4: 37-66.

García Borja, P.; Pérez Jordà, G. (2012): Ensayo tipológico para el estudio de cerámica prehistórica del País Valencià. Lucentum, XXXI: 31-59. DOI: http://dx.doi.org/10.14198/LVCENTVM2012.31.03

García Borja, P.; Verdasco Cebrián, C.; Muñoz Abril, M.; Carrión Marco, Y.; Pérez Jordá, G.; Tormo Cuñat, C.; Trelis Martí, J. (2007): Materiales arqueológicos del Bronce Final aparecidos junto al Barranc del Botx (Crevillent, Alacant). Recerques del Museu d'Alcoi 16: 89-112. 
García Cano, J.M. (1997): Las necrópolis ibéricas de Coimbra del Barranco Ancho (Jumilla, Murcia). Universidad de Murcia, Murcia.

García Menárguez, A.; Prados, F. (2014): La presencia fenicia en la península Ibérica: El Cabezo Pequeño del Estaño (Guardamar del Segura, Alicante). Trabajos de Prehistoria, 71 (1): 113-133. http://dx.doi. org/10.3989/tp.2014.12127

González Prats, A. (1979): Excavaciones en el yacimiento protohistórico de la Peña Negra, Crevillente (Alicante): $1 .{ }^{a}$ y 2. ${ }^{a}$ campañas. Ministerio de Cultura, Madrid.

González Prats, A. (1983): Estudio Arqueológico del poblamiento antiguo de la Sierra de Crevillente (Alicante). Anejo I de Lvcentvm. Universidad de Alicante, Alicante.

González Prats, A. (1990): Nueva luz sobre la protohistoria del Sudeste. Universidad de Alicante, Alicante.

González Prats, G. (2002). La necrópolis de cremación de les Moreres (Crevillente, Alicante, España): siglos IX-VII a.C. Seminarios Internacionales sobre temas Fenicios - Universidad de Alicante. Alicante.

González Prats, A. (ed.) (2011). La Fonteta. Excavaciones de 1996-2002 en la colonia fenicia de la actual desembocadura del río Segura (Guardamar del Segura, Alicante). Seminarios Internacionales sobre Temas Fenicios, Alicante.

González Prats, A. (2011a): Memoria de las excavaciones. En A. González (ed.), La Fonteta. Excavaciones de 1996-2002 en la colonia fenicia de la actual desembocadura del río Segura (Guardamar del Segura, Alicante). Seminarios Internacionales sobre Temas Fenicios, Alicante: 7-86.

González Prats, A. (2011b): Las ánforas (Tipos 1 a 6). En A. González (ed.), La Fonteta. Excavaciones de 1996-2002 en la colonia fenicia de la actual desembocadura del río Segura (Guardamar del Segura, Alicante). Seminarios Internacionales sobre Temas Fenicios, Alicante: 291-374.

González Prats, A.; Lorrio Alvarado, A. (inédito): La campaña de excavaciones de 1987 en La Penya Negra de Crevillent (Cortes $F$ y $G$ ). Una reconsideración sobre la posición estratigráfica de los talleres metalúrgicos del Bronce Final. Informe de investigación inédito.

Grau Almero, E. (inédito). Informe antracológico sobre el Castellar de Librilla (Murcia). Informe de investigación inédito.

Grau Mira, I. (2016): Archaeological surveys in areas with a high density of artefacts: analysis and interpretation proposals. Quaternay International 435 (B): 71-82. http://dx.doi.org/10.1016/j. quaint.2015.12.063

Hernández Carrión, E.; Gil González, F. (2001-2002): Encachados tumulares del Bronce Final / Hierro Antiguo en la necrópolis del Collado y Pinar de Santa Ana (Jumilla, Murcia). Anales de Prehistoria y Arqueología, 16-17: 73-94.

Jover Maestre, F.J.; Lorrio Alvarado, A.; Díaz Tena, M.A. (2016): El Bronce Final en el Levante de la península Ibérica: bases arqueológicas y periodización. Complutum, 27 (1): 81-108. http://dx.doi. org/10.5209/CMPL.53218

Lillo Carpio, P.A. (1999): El santuario ibérico de La Luz. Asociación Patrimonio Siglo XXI, Murcia.

Lomba Maurandi, J. (1995): Un nuevo yacimiento del Bronce Final con cabañas de planta oval en Murcia: la Serrecica (Totana), en Actas del XXII Congreso Nacional de Arqueología. Junta de Galicia, Vigo: 95-98.

Lomba Maurandi, J.; Cano Gomáriz, M. (2002): El Cabezo de la Fuente del Murtal (Alhama): Definición e interpretación de una fortificación de finales del siglo VII a.C. e inicios del VI en la rambla de Algeciras (Alhama de Murcia, Murcia). Memorias de Arqueología, 11: 165-204.

Lorrio Alvarado, A. (2008). Qurénima: el Bronce Final del sureste de la Península Ibérica. Real Academia de la Historia, Madrid.

Lorrio Alvarado, A.; Pernas García, S.; Torres Ortiz, M. (2016): Puntas de flecha orientalizantes en contextos urbanos del Sureste de la Península Ibérica: Peña Negra, La Fonteta y Meca. CuPAUAM, 42: 9-78. http://dx.doi.org/10.15366/cupauam2016.42.001

Lorrio Alvarado, A.; Trelis Martí, J.; Pernas García, S. (2017): La Penya Negra (Crevillent - Alacant): a la recerca de la ciutat d'Herna. La Rella, 30: 75-116.

López Castro, J.L.; Martínez Hahnmüller, V.; Moya Cobos, L.; Pardo Barrionuevo, C. (2011): Baria I. Excavaciones arqueológicas en Villaricos. La excavación de urgencia de 1987. Universidad de Almería, Almería.

Martínez Padilla, C.; Botella López, M.C. (1980): El Peñón de la Reina (Alboloduy, Almería). Ministerio de Cultura. Madrid. 
Mayoral Herrera, V.; Cerrillo Cuenca, E.; Celestino Pérez, S. (2009): Métodos de prospección arqueológica intensiva en el marco de un proyecto regional: el caso de la comarca de La Serena (Badajoz). Trabajos de Prehistoria, 66 (1): 7-25. DOI: https://doi.org/10.3989/tp.2009.09010

Molina González, F. (1978): Definición y sistematización del Bronce Tardío y Final en el Sudeste de la Península Ibérica. Cuadernos de Prehistoria de la Universidad de Granada, 3: 159-232.

Nieto Gallo, G. (1947): La necrópolis hispánica del Cabecico del Tesoro Verdolay (Murcia). En Crónica del III Congreso Arqueológico del Sureste Peninsular. Junta Municipal de Arqueología y Museo de Cartagena, Cartagena: 176-183.

Pla Orquín, R. (2014): Tipo 43. Tinajas o píthoi. En A. González (Coord.), La Fonteta, 2. Estudio de los materiales arqueológicos hallados en la colonia fenicia de la actual desembocadura del río Segura (Guardamar del Segura, Alicante). Tomo 2. Seminarios Internacionales de sobre Temas Fenicios, Alicante: 691-728.

Prados Martínez, F.; García Menárguez, A.; Jiménez Vialás, H. (2018): Metalurgia fenicia en el sureste ibérico: el taller del Cabezo Pequeño del Estaño (Guardamar, Alicante). Complutum 29 (1): 79-94. https://doi.org/10.5209/CMPL.62396

Puente de Gracia, V.M. (2016): Área de captación de recursos ferralíticos en el poblado de El Castellar de Librilla (Murcia). Siglos VIII al IV a.C. En A. Fernández (ed.), I Encuentro de jóvenes investigadores en Arqueología de la Región de Murcia: de la arqueología prehistórica a la arqueología industrial. EDITUM, Murcia: 71-101.

Renzi, M. (2013): La metalurgia del yacimiento fenicio de La Fonteta (Guardamar del Segura, Alicante). Biblioteca Praehistorica Hispana, Madrid.

Romero Díaz, M.A.; Belmonte Serrato, F. (2008): Erosión en forestaciones aterrazadas en medios semiáridos: Región de Murcia. EDITUM. Murcia.

Ros Sala, M. M. (1986-1987): El poblado de Santa Catalina del Monte: una aproximación a la urbanística del siglo VI a.C. en el ámbito territorial del eje Segura-Guadalentín. Cuadernos de Prehistoria y Arqueología 13-14: 77-88.

Ros Sala, M. M. (1988): Continuidad y cambio durante el siglo VI a.C. en el Sureste: la realidad de un poblado indígena (El Castellar de Librilla, Murcia). Anales de Prehistoria y Arqueología, 4: 83-100.

Ros Sala, M. M. (1989): Dinámica urbanística y cultura material del Hierro Antiguo en el valle del Guadalentín. Colegio Oficial de Arquitectos de Murcia - Universidad de Murcia, Murcia.

Ros Sala, M. M. (1990): Datos para una definición del Bronce Final Pleno en el Altiplano Yecla-Jumilla: las cazuelas carenadas de Coimbra del Barranco Ancho (Jumilla), Trabajos de Prehistoria, 47: 351-362.

Ros Sala, M. M. (1993): El trabajo del hierro en el poblado protohistórico de El Castellar de Librilla (Murcia). I: análisis arqueológico. En S.F. Ramallo; A.M. Muñoz; M.M. Ros; R. Arana (coords.), Metalurgia en la Península Ibérica durante el primer milenio a.C.: estado actual de la investigación. Publicaciones Universidad de Murcia, Murcia: 71-110.

Ros Sala, M. M. (2017): Nuevos datos en torno a la presencia fenicia en la Bahía de Mazarrón (Sureste Ibérico). En Prados Martínez, F.; Sala Sellés, F. (coords.), El Oriente de Occidente. Fenicios y púnicos en el área ibérica. Universidad de Alicante - Centro de Estudios Fenicios y Púnicos, Alicante: 79-104.

Ros Sala, M. M.; Brotons Yagüe, F.; Ramallo Asensio, S. F. (2016): Aproximación al horizonte PreibéricoIbérico Antiguo en el noroeste murciano: la prospección del oppidum de Los Villares del Estrecho de las Cuevas de la Encarnación (Caravaca de la Cruz). En Homenaje a la profesora Concepción Blasco Bosqued. Anejos a Cuadernos de Prehistoria y Arqueología Universidad Autónoma de Madrid 2: 219239.

Ros Sala, M.M.; Cutillas Victoria, B. (en prensa): Territorio y paisajes de la producción y el comercio fenicio en la Bahía de Mazarrón (ss. VIII-VI a.C.). En Coloquio Internacional "Fenicios y cartagineses, del cabo Artemision al río Malaka. Explotación territorial y comercio mediterráneo”, Almería.

Ros Sala, M.M.; Navarro Hervás, F.; Rodríguez Estrella, T. (2014): Génesis y evolución de un paisaje semiárido mediterráneo: el caso del entorno de Punta de los Gavilanes. Puerto de Mazarrón (Murcia). En J.M. López (ed.), Uso y gestión de recursos naturales en medios semiáridos del ámbito mediterráneo. Universidad Popular de Mazarrón, Mazarrón: 273-290.

Rouillard, P.; Gailledrat, E.; Sala Sellés, F. (2007): L'établissement protohistorique de La Fonteta (fin VIIIe -VIe siècle av. J.-C.). Casa de Velázquez, Madrid.

Ruiz Sanz, M. J. (1998): Excavaciones de urgencia en el poblado de Santa Catalina del Monte (Verdolay, Murcia). Memorias de Arqueología 7: 77-115. 
Simón García, J. L.; Hernández Carrión, E.; Gil González, F. (1999): La metalurgia en el Altiplano de Jumilla-Yecla. Prehistoria y Protohistoria, Caja de Ahorros del Mediterráneo, Jumilla.

Soriano Boj, S., Jover Maestre, F. J.; López Seguí, E. (2012): Sobre la fase orientalizante en las tierras meridionales valencianas: el yacimiento de Casa de Secà (Elche, Alicante) y la dinámica del poblamiento en el «Sinus Ilicitanus». Saguntum 44: 77-97. https://doi.org/10.7203/SAGVNTVM.44.1772

Trelis Martí, J. (1996): Aportaciones al conocimiento de la metalurgia del Bronce Final en el sureste peninsular: el conjunto de moldes de El Bosch (Crevillente-Alicante). En XXIII Congreso Nacional de Arqueología. Ayuntamiento de Elche, Elche: 185-190.

Trelis Martí, J.; Molina Mas, F. A. (2017): Control y defensa del territorio de la Penya Negra (Crevillent, Alicante): los fortines de «Les Barricaes» y «El Cantal de la Campana». En F. Prados Martínez y F. Sala Sellés (Eds.). El Oriente de Occidente. Fenicios y púnicos en el área ibérica. Alicante: Universidad de Alicante - Centro de Estudios Fenicios y Púnicos: 155-176.

Trelis Martí, J.; Molina Mas, F. A.; Esquembre Bebia, M. A.; Ortega Pérez, J. R. (2004): El Bronce Tardío e inicios del Bronce Final en el Botx (Crevillent, Alicante): Nuevos hallazgos procedentes de excavaciones de salvamento. En L. Hernández y M.S. Hernández (eds.), La Edad del Bronce en tierras valencianas y zonas limitrofes. Ayuntamiento de Villena. Villena: 319-324.

Van Dommelen, P. (1998): On colonial grounds: a comparative study of colonialism and rural settlement in first millennium $B C$ west central Sardinia. University of Leiden, Leiden.

Vives-Ferrándiz, J. (2005): Negociando encuentros: situaciones coloniales e intercambios en la costa oriental de la Península Ibérica (ss. VIII-VI a.C.). Cuadernos de Arqueología Mediterránea 12. Bellaterra, Barcelona. 